\title{
TSPO PET Imaging: From Microglial Activation to Peripheral Sterile Inflammatory Diseases?
}

\author{
Bérenger Largeau, ${ }^{1}$ Anne-Claire Dupont, ${ }^{1,2}$ Denis Guilloteau, ${ }^{1,2}$ \\ Maria-João Santiago-Ribeiro, ${ }^{1,2}$ and Nicolas Arlicot ${ }^{1,2}$ \\ ${ }^{1}$ CHRU Tours, 2 Boulevard Tonnellé, 37044 Tours, France \\ ${ }^{2}$ Institut National de la Santé et de la Recherche Médicale U930, 10 Boulevard Tonnellé, 37032 Tours, France \\ Correspondence should be addressed to Bérenger Largeau; berenger.largeau@etu.univ-tours.fr
}

Received 26 May 2017; Revised 1 August 2017; Accepted 7 August 2017; Published 25 September 2017

Academic Editor: Anne Roivainen

Copyright (C) 2017 Bérenger Largeau et al. This is an open access article distributed under the Creative Commons Attribution License, which permits unrestricted use, distribution, and reproduction in any medium, provided the original work is properly cited.

\begin{abstract}
Peripheral sterile inflammatory diseases (PSIDs) are a heterogeneous group of disorders that gathers several chronic insults involving the cardiovascular, respiratory, gastrointestinal, or musculoskeletal system and wherein inflammation is the cornerstone of the pathophysiology. In PSID, timely characterization and localization of inflammatory foci are crucial for an adequate care for patients. In brain diseases, in vivo positron emission tomography (PET) exploration of inflammation has matured over the last 20 years, through the development of radiopharmaceuticals targeting the translocator protein-18 $\mathrm{kDa}$ (TSPO) as molecular biomarkers of activated microglia. Recently, TSPO has been introduced as a possible molecular target for PSIDs PET imaging, making this protein a potential biomarker to address disease heterogeneity, to assist in patient stratification, and to contribute to predicting treatment response. In this review, we summarized the major research advances recently made in the field of TSPO PET imaging in PSIDs. Promising preliminary results have been reported in bowel, cardiovascular, and rheumatic inflammatory diseases, consolidated by preclinical studies. Limitations of TSPO PET imaging in PSIDs, regarding both its large expression in healthy peripheral tissues, unlike in central nervous system, and the production of peripheral radiolabeled metabolites, are also discussed, regarding their possible consequences on TSPO PET signal's quantification.
\end{abstract}

\section{The Sterile Inflammatory Response and PET Imaging of Inflammation}

Inflammation and its protagonist, inflammatory cells, act as the initial host defense to struggle against infection and injury. Immune system diseases can be dichotomized into autoimmune disorders, in which several actors lead to intrinsic hyperactivity of sensor/pattern-recognition receptor function, causing exacerbate and dysregulated immune response [1] and immunodeficiency diseases (i.e., inherited/primary or acquired/secondary), characterized by an inability of immune system to contain infectious disease and cancer development [2]. In both cases, the inflammatory processes are unappropriated; this explains the paradoxical relationship between immunodeficiency diseases and autoimmunity [3]. In inflammatory conditions, following exposure to aseptic stimulus involving physical chemical or metabolic signal such as burns, trauma, and dead cells, a cascade of response will be initiated by the release of local chemokines, interleukins, and prostaglandins, which are well-known proinflammatory mediators [4, 5]. Monocytes, macrophages, dendritic cells, and neutrophils are first-line immune effectors located in the interface between innate and adaptive immunity. Apart from autoimmunity disorders, noninfectious/sterile inflammatory diseases include various conditions where the leading cause of inflammation is acute and/or chronic exposure to irritant particles [5]. These sterile stimuli are different in nature and can be induced by drug therapy [6], alcohol consumption [7], exogenous particulates such as silica dioxide [8], asbestos [8], cigarette smoke [9], or endogenous particulates as well as monosodium urate [10], amyloid- $\beta$ [11], and cholesterol [12]. Macrophages are a key player in the pathophysiology 
of sterile etiology, autoimmunity disorders [13], and irritant particles mediated diseases [5]. Macrophage activation starts with a proinflammatory phase, called M1 state. Sterile injuries provoke inflammation similar to injury caused by pathogens but M1b macrophage phenotype predominantly develop, before being polarized into M2 phenotype which induce anti-inflammatory/profibrotic response [14]. Given the fact that macrophages play a crucial role in sterile inflammatory processes, macrophage imaging appears to be a promising approach to assess, better characterize, and improve the diagnosis of disorders related to sterile inflammation.

Diagnosis of most peripheral sterile inflammatory diseases (PSIDs) is based on history, clinical symptoms, biology, serology, and conventional imaging technique such as radiological analysis or magnetic resonance imaging (MRI). Concerning its signs and clinical features, the inflammatory process is very stereotypic and nonspecific [5] to such an extent that the only symptoms can be asthenia, arthralgia, and fever. Furthermore, in front of inflammatory syndrome, clinicians have to make a decision about an infectious or sterile etiology and, sometimes, practitioners in internal medicine have recourse to trial corticosteroid therapy or empiric antibiotic therapy to statute despite the risk of complicating ulterior diagnosis [15]. Indeed, corticosteroids or anti-infectious drug could conceal the pathogenic process and therefore make uninformative conventional imaging techniques due to a lack of sensitivity, so the residual disease remains inaccessible. Similarly, inflammatory foci cannot be detected in the early phase of development because of the lack of substantial anatomical changes at this time. In front of several conventional exam limitations (e.g., invasive, lack of repeatability) and in order to investigate PSIDs by a deeper approach and to access pathophysiology, the use of molecular imaging and especially PET imaging has increased significantly in recent years. PET is a molecular and functional imaging modality, which permits repeated and noninvasive determination and quantification of specific biological and pharmacological processes [16] whose interest is in early diagnosis and to monitor/follow up the residual disease is promising. ${ }^{18}$ F-FDG represents the most widely used PET tracer and many authors have elucidated in detail relationship between inflammatory response, local hyperaemia, and hypervascularisation and uptake of ${ }^{18} \mathrm{~F}$ FDG $[17,18]$. Various PSIDs have been investigated with ${ }^{18} \mathrm{~F}$ FDG including atherosclerosis [19], vasculitis [20], valvular inflammation [21], myocardial inflammation [22], rheumatoid arthritis [23], and Crohn's disease [24]. Nevertheless, ${ }^{18} \mathrm{~F}-\mathrm{FDG}$ is a glucose analog which indicates an increase of glucose consumption, which in itself can be indicative of other on-going processes such as cancer, cell regeneration, or muscle contraction as seen in peristalsis. Furthermore, another limitation concerning its pharmacokinetic, the renal pathway by which ${ }^{18} \mathrm{~F}$-FDG is eliminated, obstructs the image quantification [25].

Choline as an important precursor of membrane phospholipids has been labelled to image inflammatory diseases such as atherosclerosis [26-28] with a greater sensitivity in detecting atherosclerotic plaques than ${ }^{18}$ F-FDG [28].
Besides metabolic PET tracers of inflammatory cells (i.e., ${ }^{18} \mathrm{~F}$ FDG and ${ }^{18} \mathrm{~F}$-Choline), radioligands have been developed to evaluate more accurately peripheral sterile inflammatory processes. Among these, membrane receptor such as $18 \mathrm{kDa}$ translocator protein (TSPO) and B lymphocyte CD20 antigen [29], cytokines like cyclooxygenase subtype 2 [30], matrix metalloproteinase [31], interleukin-2 [32] or endothelial adhesion proteins such integrin $\alpha \mathrm{v} \beta 3$ [33], vascular adhesion protein-1 [34], and vascular cell adhesion molecule-1 [35] have been targeted. In this review, we focus on the most recent preclinical and clinical applications of TSPO PET imaging in PSIDs and discuss the potential added value in the clinical practice.

\section{TSPO PET Tracers}

TSPO is a highly hydrophobic five-transmembrane domain protein mainly situated in the outer mitochondrial membrane and is highly expressed in macrophages [36, 37]. TSPO is widely distributed in most peripheral organs including kidneys, nasal epithelium, adrenal glands, lungs, and heart, whilst the highest concentrations are in the steroid producing tissues, and is also minimally expressed in resting microglial cells in the healthy brain [38]. Numerous TSPO PET tracers have been developed and used mainly for the imaging of neuroinflammation [39].

In addition to many endogenous compounds like cholesterol or porphyrin, TSPO binds a range of synthetic ligands. Historically, the benzodiazepine ${ }^{11} \mathrm{C}-\mathrm{Ro5}-4864$ was the first ligand able to discriminate peripheral from central benzodiazepine receptors [40]. Over the past few years, several structure activity relationship studies have established that four main domains are necessary for a ligand to interact with the TSPO, three major lipophilic regions, and one hydrogen-bond donor group [41]. Thus, several classes of TSPO radioligands have been synthesized, with, for most of them, the availability of compounds radiolabelled with carbon-1 $\left({ }^{11} \mathrm{C}\right)$ or fluorine-18 $\left({ }^{18} \mathrm{~F}\right)$. The most widely used TSPO PET radiopharmaceutical, namely, ${ }^{11} \mathrm{C}-(\mathrm{R})-\mathrm{PK} 11195$, an isoquinoline carboxamide developed in the early 1980s, was the first nonbenzodiazepine type compound identified to bind to TSPO with high affinity (human dissociation constant, $K d=2 \mathrm{nM}$ ) [42]. Despite having been tagged as the gold standard of TSPO ligands, ${ }^{11} \mathrm{C}$-(R)-PK11195 has several drawbacks including the short half-life of carbon-11, a low brain bioavailability, and a poor signal-to-noise ratio due to high nonspecific binding [43]. To counteract these limitations, there has been a great effort for the development of second-generation TSPO PET radiotracers. Among them, the derivatives of phenoxyarylacetamides $\left({ }^{11} \mathrm{C}\right.$-DAA1106, ${ }^{11} \mathrm{C}$ PBR28, ${ }^{11}$ C-PBR06, and ${ }^{18}$ F-FEPPA) [44-47], designed from a chemical structure based on the opening of the diazepine ring of Ro5-4864, the derivatives of imidazopyridines $\left({ }^{11} \mathrm{C}\right.$ CLINME), and the derivatives of pyrazolopyrimidines $\left({ }^{18} \mathrm{~F}\right.$ DPA-714) [48] are included.

Furthermore, a single nucleotide polymorphism in the TSPO gene (rs6971) leading to an amino-acid substitution (A147T) has been identified [49]. This polymorphism affects 
TABLE 1

\begin{tabular}{|c|c|c|c|c|}
\hline Applications & Population/Animal models & Radioligand & Main findings & Ref. \\
\hline Preclinical & $\begin{array}{l}\text { (i) TSPO PET on day } 8 \text { after DSS- and } \\
\text { TNBS-induced IBD in rats } \\
\text { (ii) } 6 \text { rats were followed up over } 22 \\
\text { days }\end{array}$ & ${ }^{18}$ F-DPA-714 & $\begin{array}{l}\text { (i) Significantly increased tracer uptake in } \\
\text { the rat colon in both groups, DSS and } \\
\text { TNBS, compared to controls } \\
\text { (ii) Increased tracer binding until day } \\
8 / 10 \text { then tracer uptake decreased slowly }\end{array}$ & Bernards et al. (2014) [25] \\
\hline
\end{tabular}

DSS, dextran sodium sulfate; IBD, inflammatory bowel disease; TNBS, trinitrobenzenesulfonic acid.

the binding affinity properties of the most of TSPO with a huge heterogeneity in PET images and their associated quantitative data. Three distinct binder statuses have been identified: $\mathrm{HAB}$, high- (A/A; 70\%), MAB, mixed- $(\mathrm{A} / \mathrm{T}$; $21 \%$ ), and LAB, low-affinity binders (T/T; 9\%) [50]. The fact that the second-generation radiopharmaceuticals have been found to be sensitive to this polymorphism leads searchers to develop rs6971-insensitive radioligands. For this purpose, ${ }^{18}$ F-GE180, a third-generation TSPO tracers, was evaluated and seemed to be less sensitive to the TSPO-binding affinity status than the second generation [51]. Unfortunately, the small sample size and the exclusion of the LAB from this preliminary study leaded do not allow concluding that ${ }^{18} \mathrm{~F}$ GE180 is insensitive to the polymorphism. Then, a new analog of ${ }^{11} \mathrm{C}-(\mathrm{R})-\mathrm{PK} 11195$, called ${ }^{11} \mathrm{C}$-ER176, showed little sensitivity to rs6971 when tested in vitro and had high specific binding in monkey brain [52]. Nonetheless, the clinical relevance of this third-generation compound remains to be confirmed.

\section{TSPO PET Imaging of PSIDs}

3.1. Inflammatory Bowel Diseases (See Table 1). Although the etiology of inflammatory bowel diseases (IBDs), including Crohn's disease (CD) and ulcerative colitis (UC), is still unclear, it is widely accepted that both result from a mucosal immune response dysregulation in genetically predisposed individuals, for which susceptibility to IBD is mainly determined by complex interactions of environmental and genetic factors [53-55]. IBDs are characterized by various aspects of the inflammatory response, ranging from acute to chronic stages, and, in many cases, describe a cyclic evolution where attacks are interspersed with gastrointestinal stable periods. The natural history of the IBDs usually progresses to include strictures, fistulas, and abscesses [56]. Whereas in CD the whole gastrointestinal tract can be affected even if there is a predilection for ileocolonic involvement, UC is reduced to the caecum, colon, and rectum [57]. Localizing accurately the inflamed tissues is one criteria permitting differential diagnosis between the different types of IBDs and other diseases $[58,59]$. Presently, the diagnostic approach relies on various exams ranging from clinical symptoms, such as bloody diarrhea, abdominal pain, asthenia, and weight loss, to serology, endoscopic exploration, radiological analysis, and nuclear medical investigations [25]. Nevertheless, 10 to $15 \%$ of all colorectal IBDs cases cannot be classified as UC or CD [60]. In order to provide information concerning the inflammatory processes in IBD, ${ }^{18} \mathrm{~F}-\mathrm{FDG}$ PET imaging has been used in preclinical studies $[25,61,62]$ and clinical studies [61, 63-67], especially in pediatric populations [64, $65,68]$, and exhibited good diagnostic performances in patients with suspected IBD [58, 69]. Despite the wellknown TSPO overexpression in colon cancer [70] and the knowledge that TSPO regulates the growth of colorectal cancer cells [71] which is also an unfavorable prognostic factor in stage III colorectal cancer [72], the involvement of TSPO in IBDs and dysplasia has not yet been completely investigated. After 7 days of treatment by dextran sodium sulfate (DSS), in a way to induce IBD in a rat model, Ostuni and colleagues [73] reported a TSPO overexpression, assessed by immunohistochemistry, in the rat colon of treated animals. In DSS model, whereas the increase of ${ }^{18} \mathrm{~F}-\mathrm{FDG}$ colon uptake did not reach a significance level, ${ }^{18} \mathrm{~F}$-DPA-714 colon binding showed a significant increase, compared to healthy animals. In addition, the relationship between tissue expression of TSPO, objectified by immunohistochemistry, and ${ }^{18} \mathrm{~F}-\mathrm{DPA}-$ 714 uptake provides the proof-of-concept that TSPO PET radioligand can be used to evaluate dynamically peripheral inflammation [25]. These findings lead us to think that TSPO PET imaging could serve as a more precocious biomarker than ${ }^{18}$ F-FDG to highlight the inflammatory processes of IBDs. Regarding the inflammatory cascade of IBDs, a recent study established the responsibility of the interleukin-33 (IL33) pathway by modulating macrophages phenotype in IBDs [74]. Indeed, the authors demonstrated that IL-33 is involved in M2 macrophage polarization in inflamed mucosal samples from patients with IBD. Moreover, serum IL-33 levels were significantly lower in IBD's patients than those in healthy volunteers. Serum soluble suppression of tumorigenicity2 (sST2) levels and its soluble receptor were significantly correlated with the pMayo score in UC patients but not in $\mathrm{CD}$, supporting evidences that $\mathrm{UC}$ is a disorder linked to Th2-hyperpolarization in contrast to CD, which is rather Th1derived [75].

3.2. Liver Diseases (See Table 2). The expression of TSPO in the liver of healthy humans is usually low $[76,77]$. Recent evidences suggest that TSPO might be contribute to the liver damage and alcoholic hepatitis progression. Indeed, TSPO gene is upregulated in alcohol hepatitis and appears to be involved in various biological processes which are determinant in the pathophysiology of alcoholic liver disease such as regulation of reactive oxygen species, response to alcohol, negative regulation of nitric oxide pathway, and regulation of 


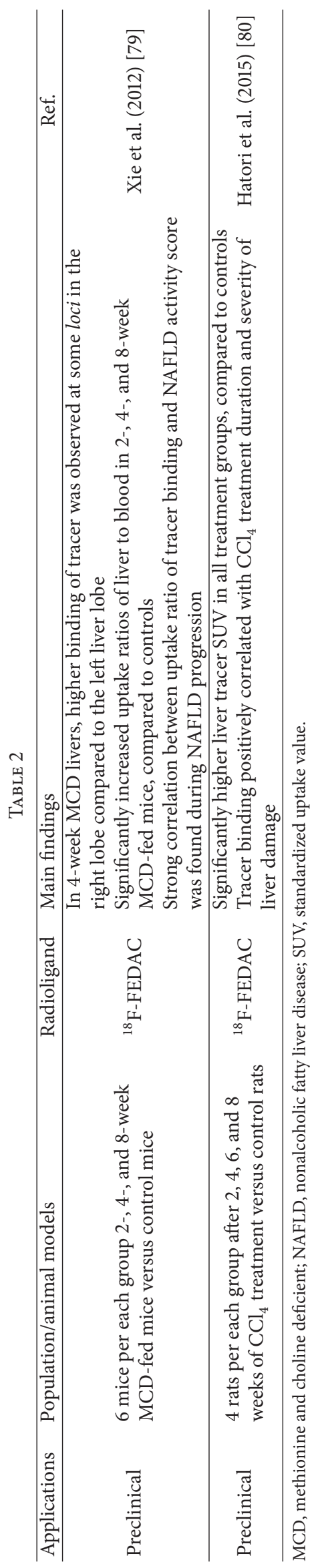


necrotic cell death [78]. Tissue analysis revealed more serious steatotic aggregates and necroinflammatory infiltration in the higher uptake region of ${ }^{18}$ F-FEDAC. Autoradiography experiments $[79,80]$ supported in vivo PET data where TSPO tracer binding was not homogeneously distributed in the livers with nonalcoholic fatty liver disease (NAFLD) [79] and in the fibrotic livers (induced by carbon tetrachloride treatment) [80]. Analysis association between ${ }^{18}$ F-FEDAC binding and NAFLD activity score is in consonance with in vitro findings where TSPO overexpression was reported in activated hepatic stellate cells [81] and in the adipocytes of stressed rats with adipocytes aggregates and neoangiogenesis process [82]. TSPO PET tracer uptake increased in parallel with liver disease severity whether it is in NAFLD [79] or in fibrosis liver models [80]. Positively correlation between hepatic TSPO and (transforming growth factor) TGF- $\beta 1 /$ (tumor necrosis factor) TNF- $\alpha$ mRNA expression [80] suggests that macrophage M1 and M2 phenotypes intervene during liver fibrosis development [83]. Complementary clinical studies with various liver diseases characterized by inflammatory processes (e.g., viral hepatitis, cholestatic hepatitis, autoimmune hepatitis, and Wilson's disease) are required to evaluate the ability of differential diagnosis of TSPO PET imaging.

3.3. Inflammatory Lung Diseases (See Table 3). In contrast to nonspecific current methods (e.g., chest radiography and computed tomography), TSPO PET imaging could potentially give quantitative information about macrophage trafficking and kinetics, in order to evaluate treatment response and contribute to our understanding of the pathophysiology of lung noninfectious inflammatory processes [84]. Moreover, invasive methods (e.g., lung biopsy and bronchoalveolar lavage) are unacceptable for repeat measurement in the context of longitudinal assessment for lung diseases [85]. Concerning single photon emission computed tomography (SPECT) scanning, although gamma-scintigraphy with ${ }^{111}$ Inlabelled granulocytes has been used to monitor migration of polynuclear cells into the lungs $[86,87]$, its metabolic activation and phenotype remain inaccessible with this nuclear exam [88].

A major concern for the meaning of this TSPO PET imaging approach is the multicellular expression of TSPO in the human lungs. In addition to resident alveolar macrophages, submucosal glands, pneumocytes, and epithelial lining of the airways expression of TSPO have been reported $[89,90]$ but not neutrophilic expression [91]. Asthma and chronic obstructive pulmonary disease (COPD) are two obstructive respiratory conditions where an important accumulation of inflammatory cells in the respiratory tract takes place and leads to chronic symptoms with periodic acute exacerbations of both asthma and COPD. The pathophysiology of these lung inflammatory disorders is distinct, involving rather excessive formation of eosinophils, mast cells, and $\mathrm{CD} 4^{+} \mathrm{T}$ cells in airways of asthmatics whereas, in COPD, typically neutrophils, macrophages, and $\mathrm{CD}^{+} \mathrm{T}$ cells infiltrate the respiratory tract [92]. TSPO seems to play a pathogenic role in asthma and COPD. Indeed, TSPO exhibited downregulated expression in patients with acute exacerbations of COPD [93] and a protein-protein interaction network analysis revealed that TSPO could be implicated in development and/or progression of asthma in children [94]. TSPO is involved in various complex cellular processes such as intracellular transportation, mitophagy, and apoptosis [95-97]. Among them, mitochondrial dysregulation and especially mitophagy represent a key player of signaling pathways relevant to remodeling in chronic remodeling lung pathologies like asthma [98] and COPD [99]. Quantitative analysis of the acquired emission TSPO PET data is in consonance with these findings where mean tracer uptake, objectified by plateau tissue/plasma, was higher in COPD patients and asthmatics than in healthy volunteers. Moreover, pulmonary TSPO PET imaging used in combination with ${ }^{18} \mathrm{~F}$-FDG indicated that metabolic activation of inflammatory cells was higher in COPD patients than in chronic asthmatics [100]. Furthermore, cigarette smoke exposure, which is the leading cause of COPD, altered directly TSPO expression, paving the way for lung cancerization [101]. It should be noted that no obvious differences are seen between patients and healthy subject in the emission images for either ${ }^{18} \mathrm{FDG}$ or ${ }^{11} \mathrm{C}$ PK11195, due to the low density of the lung (Figure 1). Significant differences are only revealed by quantitative analysis of the acquired emission data [100].

TSPO PET imaging has been used to assess, in humans, macrophages involvement in interstitial lung diseases [102]. Surprisingly, Branley et al. [85] demonstrated that TSPO expression is reduced in these lung inflammatory disorders. Given the fact that patients with interstitial lung disease showed an accumulation of intrapulmonary macrophages [103] and experimental models of pulmonary inflammation revealed to be associated with TSPO overexpression [104], authors hypothesized that macrophages phenotypically differed in these patients (i.e., macrophage with reduced TSPO expression) [102]. In parallel to the relationship between lung density and disease activity (i.e., between controls, patients treated, and drug-naive patients), ${ }^{11} \mathrm{C}$-PK11195 binding would tend to decline according to the disease burden in fibrosing alveolitis due to systemic sclerosis (FASSc) patients [85]. As a result of these achievements, TSPO PET imaging could be a decision-support exam to initiate immunosuppressive treatment in FASSc.

TSPO PET imaging did not provide unequivocal results $[85,100]$ and in front of some limitations (e.g., multicellular expression of TSPO in human lungs [89, 90], high variability in radiotracer uptake between COPD and asthmatic patients, and wide overlap between patients and controls [100]), TSPO did not seem to be a timely biomarker to diagnose and even less to improve our knowledge in lung disease pathophysiology. In addition, the apparent TSPO downregulation in interstitial lung diseases [85] and acute exacerbations of BPCO [93] should not be construed as absolute finding; indeed TSPO expression is a dynamic process and highly context-dependent, which is probably integrated in a time-dependent fashion (acute versus chronic injury). 


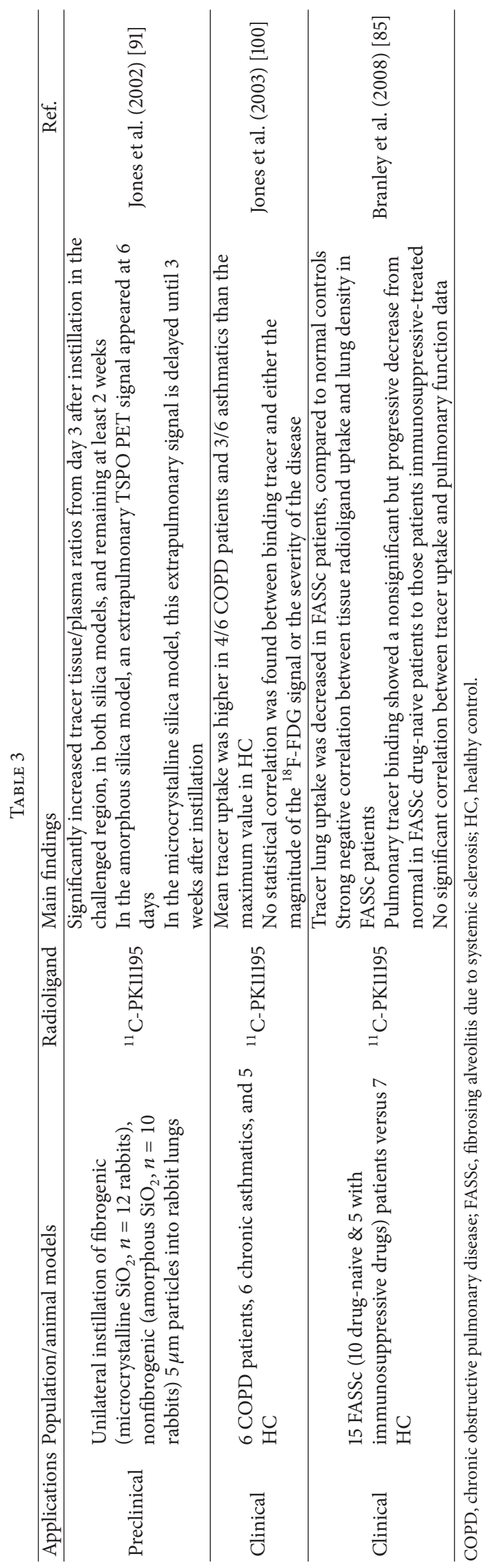




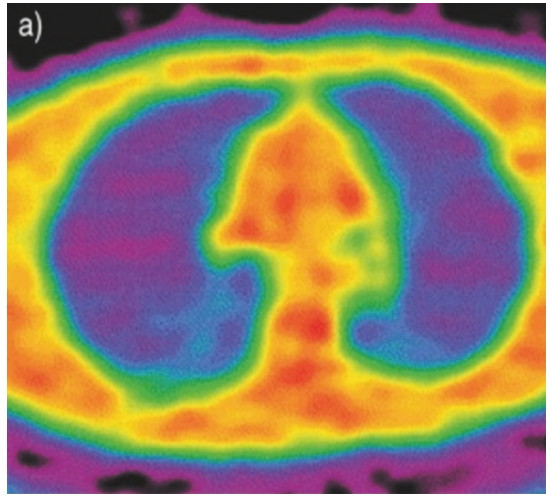

(a)

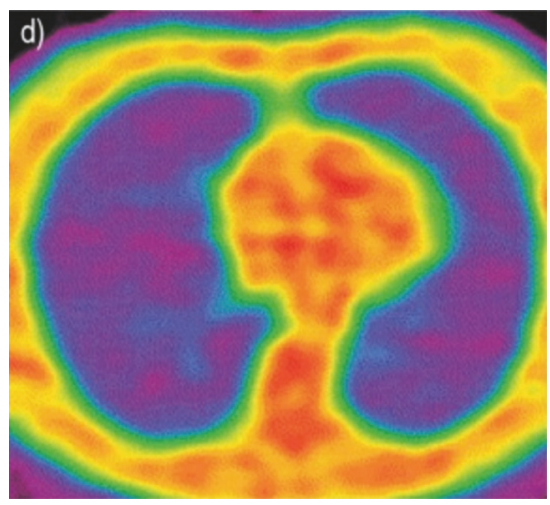

(d)

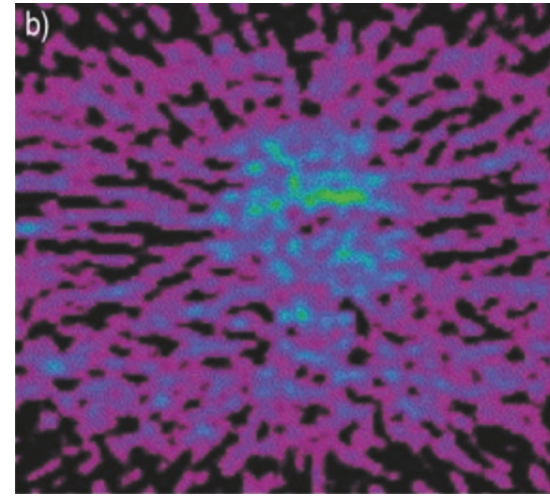

(b)

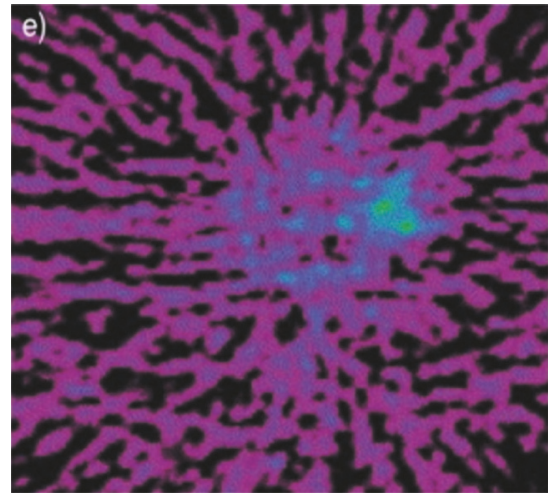

(e)

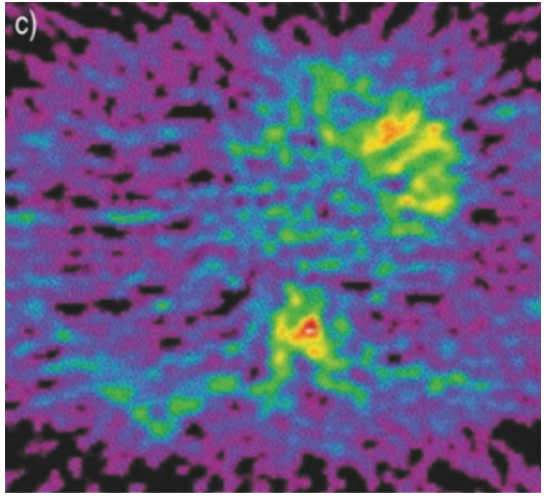

(c)

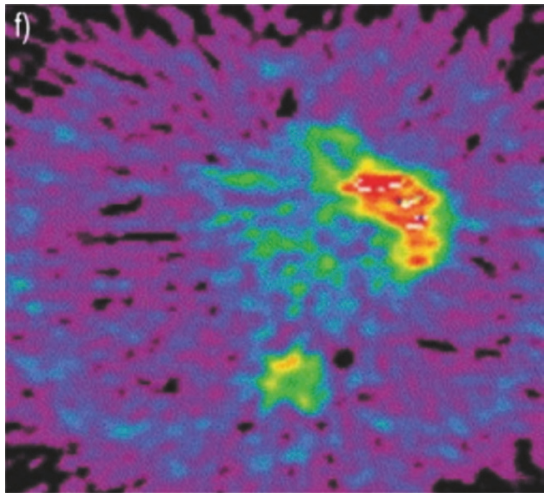

(f)

FIGURE 1: Transaxial thoracic images for transmission (a and d), ${ }^{18}$ F-FDG emission (b and e) and ${ }^{11} \mathrm{C}-\mathrm{PK} 11195$ (c and f) in a normal subject $(a-c)$, and a patient with chronic obstructive pulmonary disease (d-f) from Jones et al. (2003) [100].

3.4. Inflammatory Vasculopathies (See Table 4). TSPO is involved in pathophysiology of various cardiovascular diseases, including arrhythmia, myocardial infarction, cardiac hypertrophy, atherosclerosis, myocarditis, and large vessel vasculitis (for review see Qi et al. 2012 [105]). Among these, large vessel vasculitis represents a heterogeneous group of complex disorders (e.g., giant cell arteritis, Takayasu's arteritis) in which chronic inflammatory lesions of the blood vessels are characterized by granulomatous pan-arteritis with focal leukocytic infiltration [106]. Typical clinical symptoms include the association of blindness, stroke, claudication according to the vascular territory affected/occluded, fever, night sweats, and arthralgia [107-109]. TSPO molecular imaging using ${ }^{11} \mathrm{C}-\mathrm{PK} 11195$ provided valuable information such as presence, intensity, and localization of activated macrophages in large vessel vasculitis [36, 110]. In these studies, giant cell arteritis, Takayasu's arteritis, and lupus erythematosus patients fulfilling American College of Rheumatology diagnostic criteria [111] were enrolled. Authors defined active vasculitis as onset within the previous 3 months of any of the symptoms mentioned above and conversely asymptomatic patients' diagnosis based on absence of symptoms of active disease. The fact that TSPO PET signal was quantifiable even in some asymptomatic patients (Figure 2) paves the way of a preemptive therapeutic strategy, that is to say prior the symptoms, whereas the inflammatory process is active $[36,110]$. Although only one giant cell arteritis patient was enrolled for a longitudinal assessment of corticosteroids response, TSPO PET imaging could be a promising approach to monitor drug efficacy of immunosuppressive agents currently used and for drug development in vasculitis. Patients with large vessel vasculitis have an increased cardiovascular risk compared to the age-matched healthy population as a consequence of accelerated atherosclerosis [106].

Atherosclerosis is an inflammatory, chronic metabolic disorder of the arterial walls, in which intraplaque inflammation drives the progression and the destabilization of atheromatous lesions [112, 113]. It seems that atherosclerosis starts with the penetration of low-density lipoprotein (LDL) through a damaged endothelial wall, leading to their oxidation. These oxidized LDL particles act as autoantigens presented by macrophages which differentiate into foamy macrophages, promote the inflammation, and cause interleukins secretion [114-116]. According to its function as leader of cholesterol transport and steroidogenesis [97] and its dysregulation induced by smoke exposure [101], TSPO has been targeted in drug development of lipid-lowering therapy and "cardiovascular" anti-inflammatory/antioxidant treatment [117-119]. Autoradiography and immunostaining experiments highlighted that TSPO tracer binding concerned 


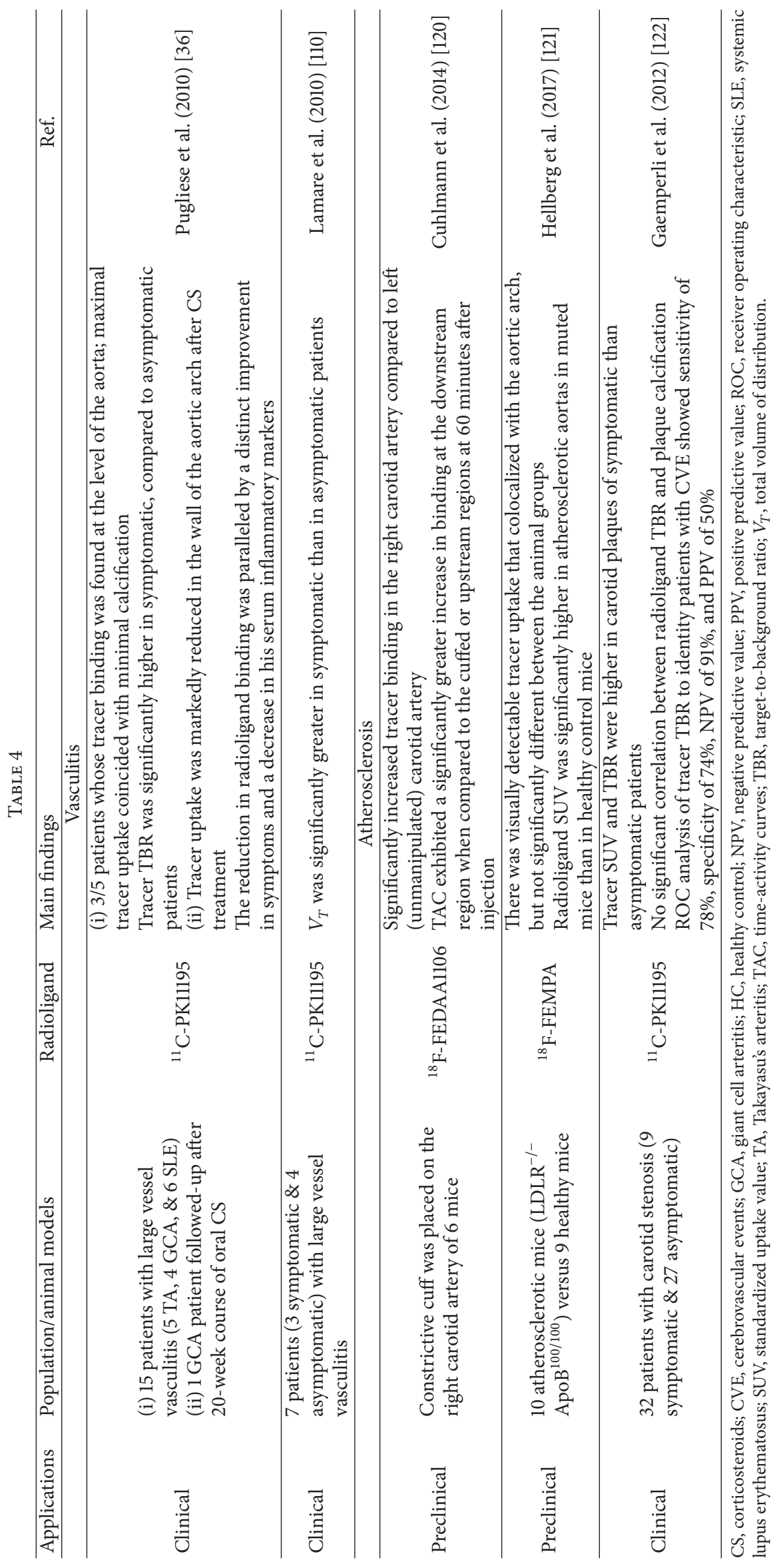




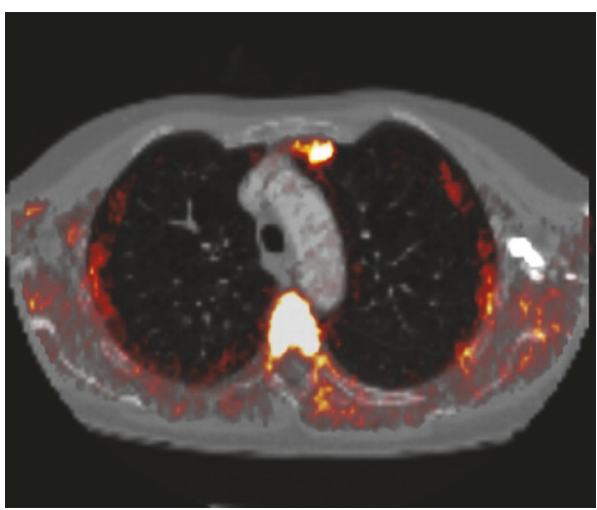

(a)

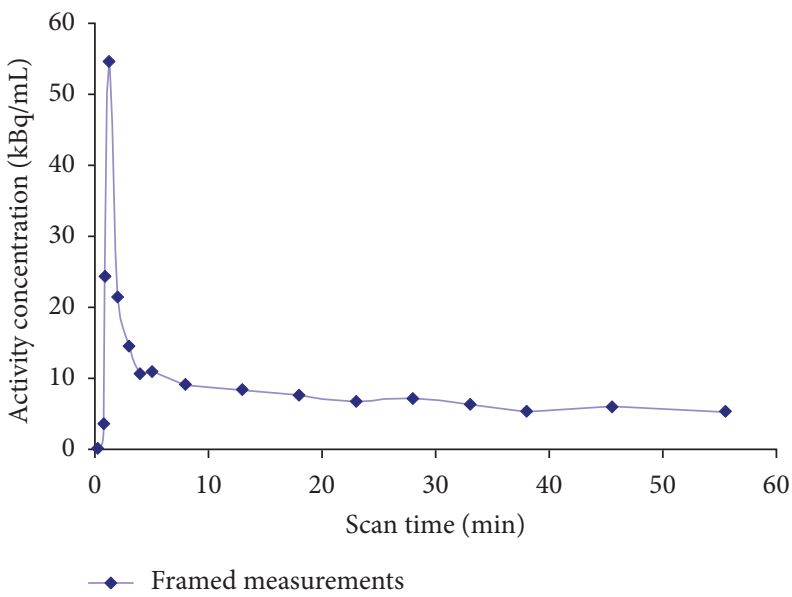

(c)

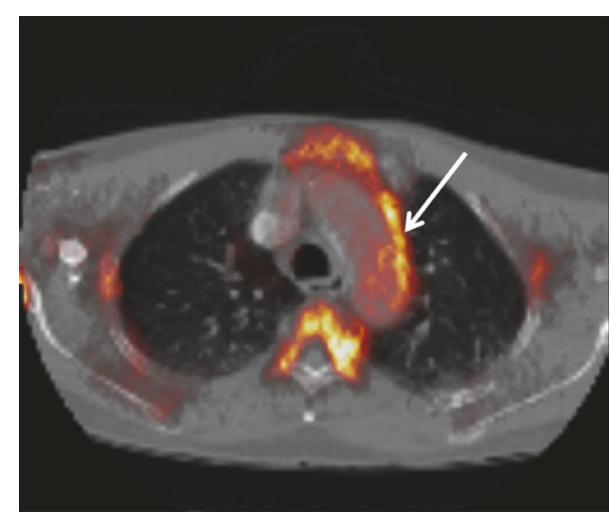

(b)

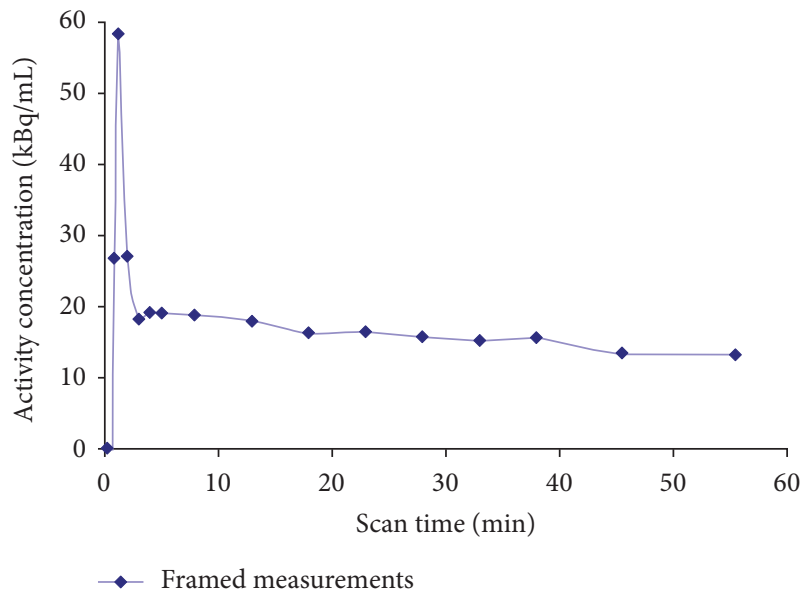

(d)

FIGURE 2: ${ }^{11} \mathrm{C}$-PK11195 PET/CT angiography of asymptomatic (a) and symptomatic (b) patient with vasculitis. Each patient is shown in transverse view. Arrow indicates inflamed region of aortic arch. Respective time-activity curves (corrected for radioactive decay) derived from aortic vessel wall (c and d) from Lamare et al. (2010) [110].

predominantly CD68-positive areas of mice carotid sections [120] and human carotid endarterectomy samples [121, 122] which contained fibrotic and calcified tissue [121]. Recent research by Chinetti-Gbaguidi and colleagues [123] revealed that RANKL (receptor activator of nuclear factor $\kappa \mathrm{B}(\mathrm{NF}-\kappa \mathrm{B})$ ligand) and MCSF (macrophage colony-stimulating factor), two major mediators of vascular calcification, are dysregulated by IL- 4 polarization (i.e., $M_{1}$ to $M_{2}$ polarization), leading macrophages surrounding atherosclerotic plaques to be unable to resorb calcification. Therefore, the lack of association between plaque calcification score and ${ }^{11} \mathrm{C}-\mathrm{PK} 11195$ target-to-background ratio (TBR) [122] could be explained by a different macrophage phenotype (i.e., $\mathrm{M}_{2}$ polarized) which would be undetectable on PET images. Moreover, in the same clinical study TSPO PET imaging of patients with carotid stenosis revealed that ${ }^{11} \mathrm{C}$-PK11195 standardized uptake value (SUV) and TBR were significantly higher in carotid atheromatous lesions of symptomatic patients (i.e., associated with stroke and transient ischemic attacks) compared to asymptomatic individuals. Surprisingly, no difference was found between the severity of carotid stenosis on CT angiography between symptomatic and asymptomatic patients [122]. Most importantly, it appears that activated macrophages, assessed by TSPO PET, were detected at a disturbed flow site located downstream from the region of stenosis [120]. Finally, multimodal imaging using ${ }^{11} \mathrm{C}$-PK11195 PET in combination with CT plaque attenuation offers good diagnostic performances to improve risk stratification in patients with asymptomatic carotid stenosis in order to anticipate cerebrovascular events [122]. Beyond this potential diagnostic role of TSPO PET scanning for atherosclerosis, TSPO might be used as a therapeutic target for atherosclerosis. Indeed, the oxidative stress induced by high fat and high cholesterol atherogenic diet in rats has been associated with a reduction of TSPObinding density [124].

3.5. Rheumatic and Musculoskeletal Disorders (See Table 5). Rheumatoid arthritis (RA) is a chronic autoimmune disease characterized by joint inflammation where the diagnosis is based on joint involvement, duration of symptoms, serology (i.e., rheumatoid factor, anticitrullinated protein antibody), and biology (i.e., erythrocyte sedimentation rate, C-reactive protein) $[126,127]$. TSPO PET imaging in various animal models of noninfectious arthritis supported the fact that 


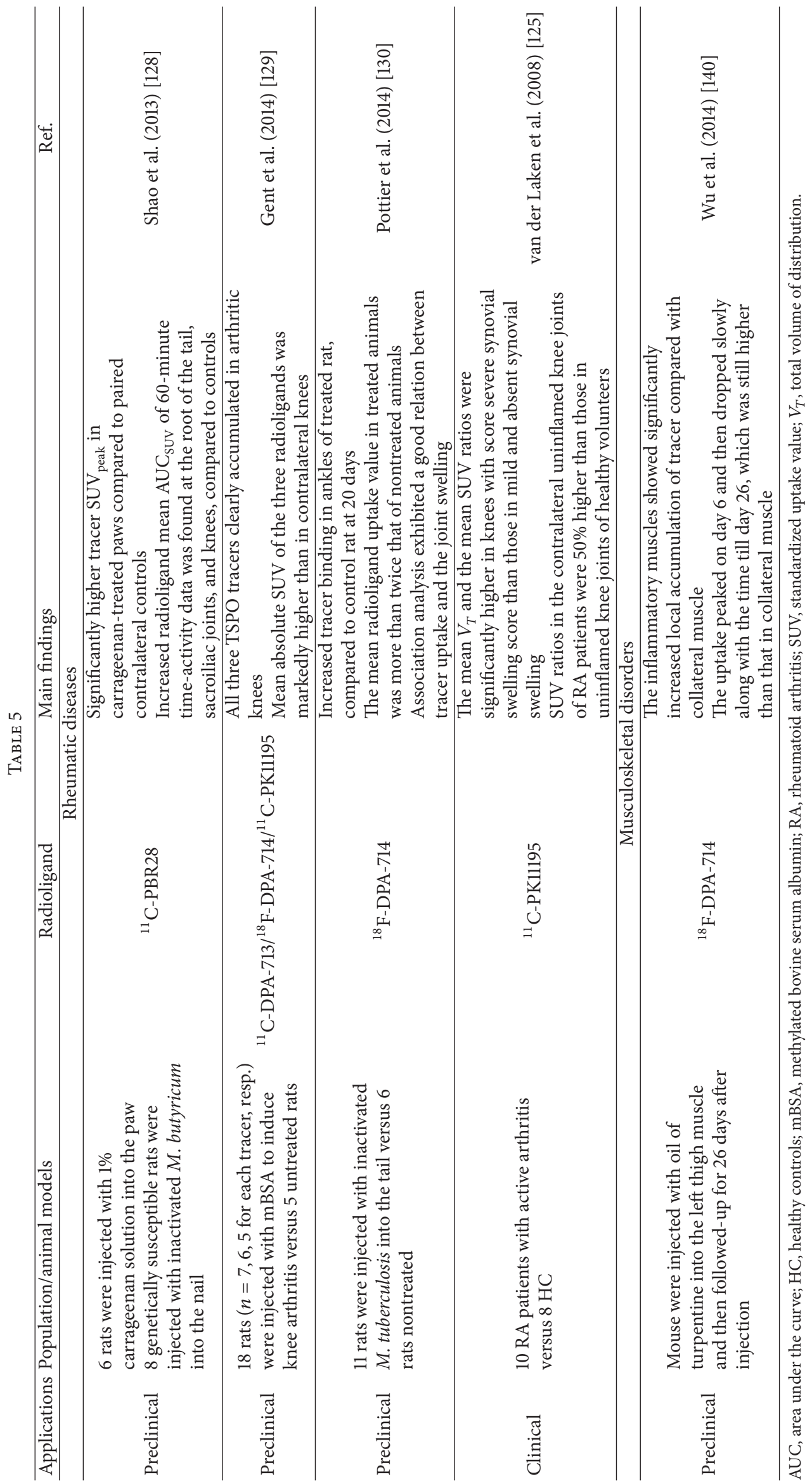



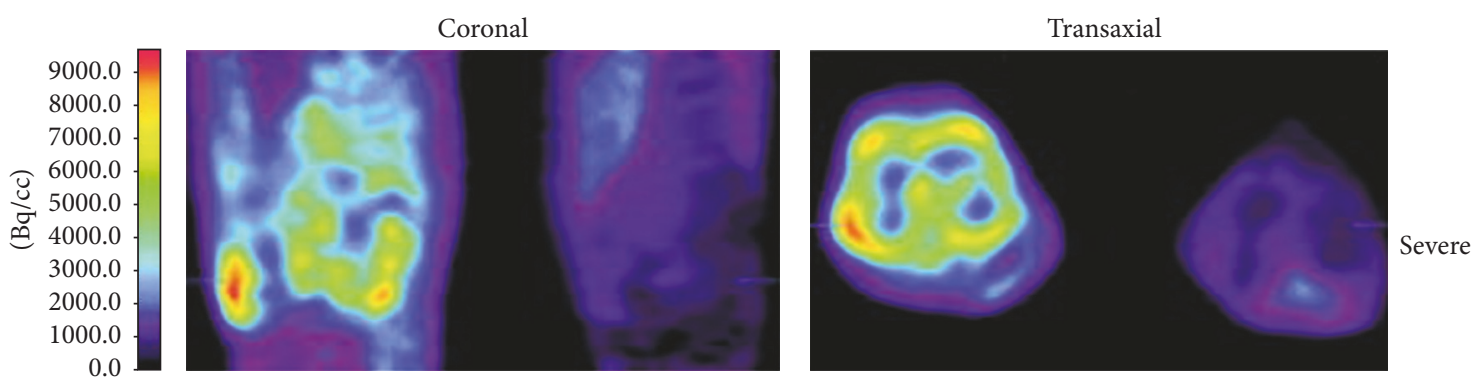

(a)
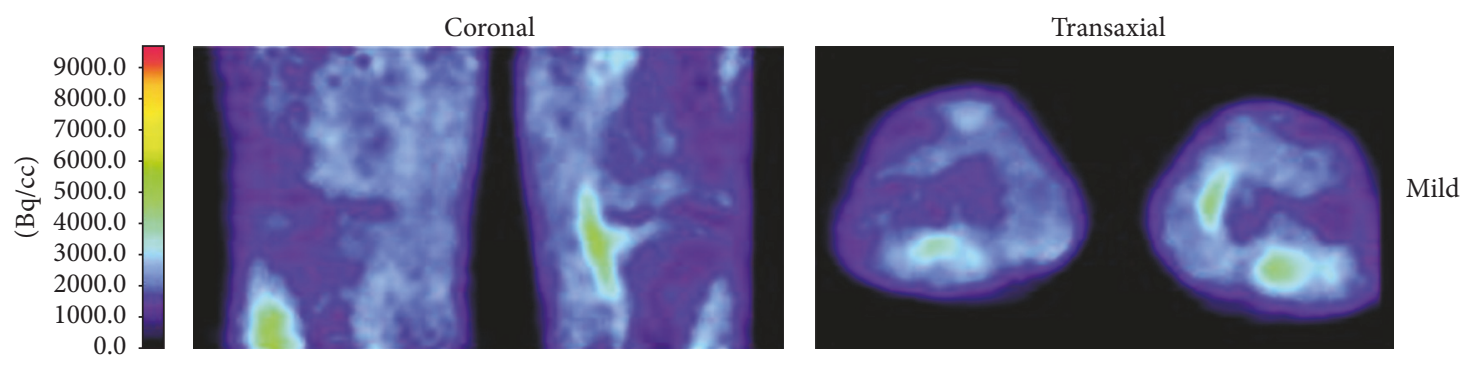

(b)
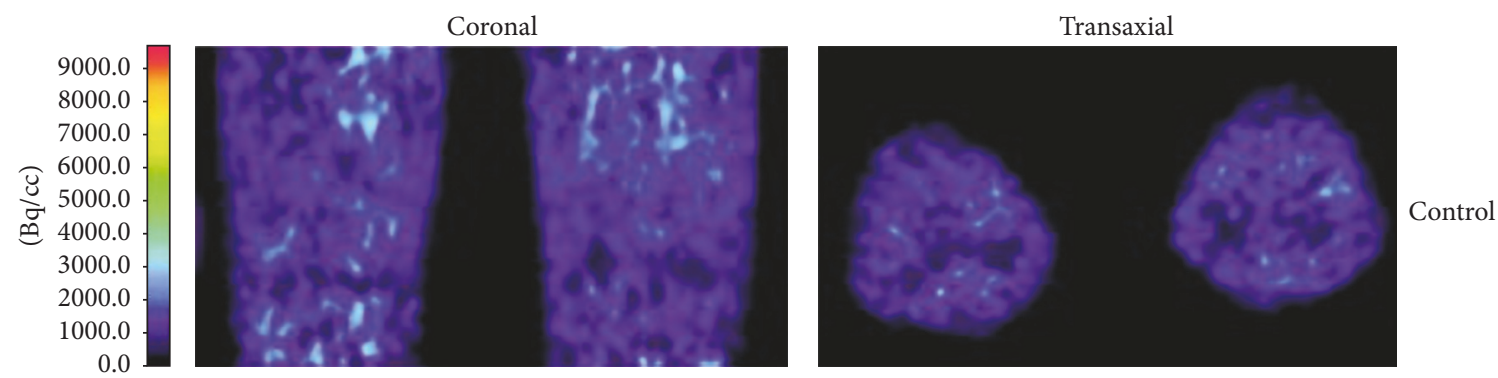

(c)

FIGURE 3: ${ }^{11} \mathrm{C}-\mathrm{PK} 11195$ PET images in coronal and transaxial directions. (a) Images of severe clinical inflammation of the right knee (depicted at the left in both images) and no clinical inflammation of the left knee in a patient with rheumatoid arthritis (RA). (b) Images of mild inflammation of both knee joints in an RA patient. (c) Images of knees without joint disease in a control subject. The different levels of tracer uptake correspond to the colors in the color bar at the left, from van der Laken et al. (2008) [125].

nuclear-based approach provides quickly information on biological functions even before anatomical alterations of bone and cartilage [128-130]. TSPO PET imaging appears to be a promising approach to follow early events in the pathophysiology of RA, suggesting that a precocity medical care should be feasible even before the structural alterations, especially as the uninflamed knee joints of RA patients showed a significant greater TSPO tracer uptake than in healthy controls [125]. Moreover, association analysis showed a good correlation between tracer binding in joints and clinical synovial swelling or macrophage infiltration in synovial tissue in preclinical [130] and clinical study [125]. Figure 3 illustrates these findings. For imaging of RA, the key limitation of TSPO PET scanning is the tracer uptake in the inflamed synovium linked to binding in surrounding bone and bone marrow (e.g., periarticular bone of joints binding), keeping from quantifying accurately uptake in the synovium [129]. Nevertheless, this problem appears to be minimized when ${ }^{18} \mathrm{~F}$-DPA tracers have been used in rat model of rheumatoid arthritis (i.e., better knee-to-bone ratios), compared to ${ }^{11} \mathrm{C}$ PK11195 [129].

\section{TSPO PET Imaging: Towards a Clinical Application for Pathologies with Both Central and Peripheral Inflammatory Component?}

TSPO PET imaging has to date been used mainly to assess microglial activation in various neurologic diseases ranging from neurodegenerative disorders such as Huntington's disease [131] and Alzheimer's disease [132] to stroke [133] and psychiatric conditions like schizophrenia [134]. The promising results of TSPO PET imaging to diagnose and characterize some PSIDs and especially atherosclerosis [122] lead us to think that, as in some central nervous system disorders such as multiple sclerosis and amyotrophic lateral sclerosis [39], a clinical application of TSPO as a biomarker 
of inflammation is possible. Nevertheless, as with neurologic disorders some limitations must be taken like spillover and partial volume effect (because of proximity of the blood pool and limited thickness of the arterial wall), a multicellular expression making mathematic model to quantify free and specific ligand binding more complex. Furthermore, in contrast to central conditions where tracer's radiolabeled metabolites are not sufficiently lipophilic to produce background noises, in PSIDs the pharmacokinetic of radiolabeled metabolites leads to hinder TSPO signal quantification. This is especially a limitation for IBDs where tracer elimination by the upper digestive tract (e.g., $\left.{ }^{18} \mathrm{~F}-\mathrm{DPA}-714\right)$ compromised TSPO quantification [25].

The strength of TSPO PET imaging could rely on the ability to detect inflammatory changes in pathologies which have central and peripheral expression, for instance, to evaluate the relationship between neuroinflammation induced by stroke and TSPO expression of atherosclerotic plaques in patients with carotid stenosis. Indeed, it allows characterizing inflammation and establishing if interplay occurred between microglial activation and peripheral macrophages. In this sense, surprising findings have been found in liver fibrosis where TSPO are not overexpressed in patients with hepatic encephalopathy [135]. Likewise, in a preclinical study, inflammation in both the gut and the brain of rats with chemically induced colitis was observed by ex vivo biodistribution but these effects could not be detected by ${ }^{11} \mathrm{C}$-PBR28 PET imaging which was likely due to insufficient resolution of the micro-PET camera [136]. Besides PSIDs, infectious diseases where TSPO PET imaging has already been investigated such as HIV infection [137] or sepsis [138] could benefit from this approach in order to know if central and peripheral inflammation is a continuum or acts independently.

\section{Conclusion}

The pathophysiologic involvement of TSPO in PSIDs is welldocumented especially in cardiovascular conditions [105] at the opposite of microglial activation in neurologic disorders which remains controversial. Limitations of TSPO PET imaging in PSIDs concern the large expression of TSPO in peripheral tissues whereas, in central nervous system, TSPO expression is low in healthy brain [39]. A body of evidence gives a M1-phenotype biomarker status of microglial TSPO expression [139]. In line with these findings, the fact that TSPO PET imaging did not highlight significant signal in some PSIDs (e.g., atherosclerosis [122], interstitial lung disease [85]), where macrophage activation is now well-documented, seems to confirm that, also in peripheral disorders, TSPO may rather to be associated with harmful inflammatory state than regenerative environment. Nevertheless these in vitro findings need to be in vivo translated [139].

\section{Conflicts of Interest}

The authors declare no conflicts of interest.

\section{Acknowledgments}

This study was supported by the French National Agency for Research ("Investissements d'Avenir" no. ANR-11-LABX0018-01), IRON, and the European Union's Seventh Framework Programme (FP7/2004-2013) under Grant Agreement no. 278850 (INMiND).

\section{References}

[1] A. A. de Jesus, S. W. Canna, Y. Liu, and R. Goldbach-Mansky, "Molecular mechanisms in genetically defined autoinflammatory diseases: disorders of amplified danger signaling," Annual Review of Immunology, vol. 33, no. 1, pp. 823-874, 2015.

[2] N. Raje and C. Dinakar, "Overview of immunodeficiency disorders," Immunology and Allergy Clinics of North America, vol. 35, no. 4, pp. 599-623, 2015.

[3] J. Sleasman, "The association between immunodeficiency and the development of autoimmune disease," Advances in Dental Research, vol. 10, no. 1, pp. 57-61, 2016.

[4] C.-J. Chen, H. Kono, D. Golenbock, G. Reed, S. Akira, and K. L. Rock, "Identification of a key pathway required for the sterile inflammatory response triggered by dying cells," Nature Medicine, vol. 13, no. 7, pp. 851-856, 2007.

[5] K. L. Rock, E. Latz, F. Ontiveros, and H. Kono, "The sterile inflammatory response," Annual Review of Immunology, vol. 28, pp. 321-342, 2010.

[6] C. Zhang, J. Feng, J. Du et al., "Macrophage-derived IL-1 $\alpha$ promotes sterile inflammation in a mouse model of acetaminophen hepatotoxicity," Cellular \& Molecular Immunology, 2017.

[7] C. Ju and P. Mandrekar, "Macrophages and Alcohol-Related Liver Inflammation," Alcohol Research: Current Reviews, vol. 37, pp. 251-262, 2015.

[8] B. T. Mossman and A. Churg, "Mechanisms in the pathogenesis of asbestosis and silicosis," The American Journal of Respiratory and Critical Care Medicine, vol. 157, no. 5, pp. 1666-1680, 1998.

[9] J. M. Craig, A. L. Scott, and W. Mitzner, "Immune-mediated inflammation in the pathogenesis of emphysema: insights from mouse models," Cell and Tissue Research, vol. 367, no. 3, pp. 591605, 2017.

[10] G. Nuki and P. A. Simkin, "A concise history of gout and hyperuricemia and their treatment," Arthritis Research and Therapy, vol. 8, supplement 1, article S1, 2006.

[11] H. L. Weiner and D. Frenkel, "Immunology and immunotherapy of Alzheimer's disease," Nature Reviews Immunology, vol. 6, no. 5, pp. 404-416, 2006.

[12] A. Gisterå and G. K. Hansson, "The immunology of atherosclerosis," Nature Reviews Nephrology, vol. 13, no. 6, pp. 368-380, 2017.

[13] K. C. Navegantes, R. Souza Gomes, P. A. T. Pereira, P. G. Czaikoski, C. H. M. Azevedo, and M. C. Monteiro, "Immune modulation of some autoimmune diseases: The critical role of macrophages and neutrophils in the innate and adaptive immunity," Journal of Translational Medicine, vol. 15, no. 1, article 36, 2017.

[14] M. Lech and H.-J. Anders, "Macrophages and fibrosis: how resident and infiltrating mononuclear phagocytes orchestrate all phases of tissue injury and repair," Biochimica et Biophysica Acta: Molecular Basis of Disease, vol. 1832, no. 7, pp. 989-997, 2013.

[15] A. Freedman, J. Williams, and R. Bellamy, "Fever of unknown origin," Clinical Medicine, vol. 8, no. 5, pp. 526-530, 2008. 
[16] D. A. Mankoff, "A definition of molecular imaging," Journal of Nuclear Medicine, vol. 48, pp. 18N-21N, 2007.

[17] R. Kubota, S. Yamada, and K. Kubota, "Intratumoral distribution of fluorine-18-fluorodeoxyglucose in vivo: high accumulation in macrophages and granulation tissues studied by microautoradiography," Journal of Nuclear Medicine, pp. 331972, 1992.

[18] T. Mochizuki, E. Tsukamoto, and Y. Kuge, "FDG uptake and glucose transporter subtype expressions in experimental tumor and inflammation models," Journal of Nuclear Medicine, vol. 42, pp. 1551-1555, 2001.

[19] S. Gogia, Y. Kaiser, and A. Tawakol, "Imaging High-Risk Atherosclerotic Plaques with PET," Current Treatment Options in Cardiovascular Medicine, vol. 18, no. 12, 2016.

[20] J. Bucerius, "Monitoring Vasculitis with 18F-FDG PET," The Quarterly Journal of Nuclear Medicine and Molecular Imaging, vol. 60, pp. 219-235, 2016.

[21] M. R. Dweck, C. Jones, N. V. Joshi et al., "Assessment of valvular calcification and inflammation by positron emission tomography in patients with aortic stenosis," Circulation, vol. 125, no. 1, pp. 76-86, 2012.

[22] W. W. Lee, B. Marinelli, A. M. van der Laan et al., "PET/MRI of inflammation in myocardial infarction," Journal of the American College of Cardiology, vol. 59, no. 2, pp. 153-163, 2012.

[23] S. Wang, Q. Xie, and W. LV, "Positron emission tomography/computed tomography imaging and rheumatoid arthritis," International Journal of Rheumatic Diseases, vol. 17, no. 3, pp. 248-255, 2014.

[24] P. B. Shyn, "18F-FDG positron emission tomography: potential utility in the assessment of Crohn's disease," Abdominal Imaging, vol. 37, no. 3, pp. 377-386, 2012.

[25] N. Bernards, G. Pottier, B. Thézé, F. Dollé, and R. Boisgard, "In vivo evaluation of inflammatory bowel disease with the aid of $\mu \mathrm{PET}$ and the translocator protein $18 \mathrm{kDa}$ radioligand $\left[{ }^{18}\right.$ F]DPA-714," Molecular Imaging and Biology, vol. 17, pp. 6775, 2014.

[26] J. Bucerius, J. Schmaljohann, I. Böhm et al., "Feasibility of 18Ffluoromethylcholine PET/CT for imaging of vessel wall alterations in humans - First results," European Journal of Nuclear Medicine and Molecular Imaging, vol. 35, no. 4, pp. 815-820, 2008.

[27] I. E. Laitinen, P. Luoto, K. Nagren et al., "Uptake of 11C-Choline in Mouse Atherosclerotic Plaques," Journal of Nuclear Medicine, vol. 51, no. 5, pp. 798-802, 2010.

[28] C. M. Matter, "18F-Choline Images Murine Atherosclerotic Plaques Ex Vivo," Arteriosclerosis, Thrombosis, and Vascular Biology, vol. 26, no. 3, pp. 584-589, 2005.

[29] L. Tran, A. D. R. Huitema, M. H. van Rijswijk et al., "CD20 antigen imaging with ${ }^{124} \mathrm{I}$-rituximab PET/CT in patients with rheumatoid arthritis," Human Antibodies, vol. 20, pp. 29-35, 2011.

[30] M. J. Uddin, B. C. Crews, K. Ghebreselasie et al., "Fluorinated COX-2 Inhibitors as Agents in PET Imaging of Inflammation and Cancer," Cancer Prevention Research, vol. 4, no. 10, pp. 15361545, 2011.

[31] D. Hartung, M. Schäfers, S. Fujimoto et al., "Targeting of matrix metalloproteinase activation for noninvasive detection of vulnerable atherosclerotic lesions," European Journal of Nuclear Medicine and Molecular Imaging, vol. 34, supplement 1, pp. S1S8, 2007.
[32] V. di Gialleonardo, A. Signore, A. W. J. M. Glaudemans, R. A. J. O. Dierckx, and E. F. J. de Vries, "N-(4- ${ }^{18} \mathrm{~F}-$ fluorobenzoyl)interleukin-2 for PET of human-activated $\mathrm{T}$ lymphocytes," Journal of Nuclear Medicine, vol. 53, no. 5, pp. 679-686, 2012.

[33] R. L. Wilder, "Integrin alpha V beta 3 as a target for treatment of rheumatoid arthritis and related rheumatic diseases," Annals of the Rheumatic Diseases, vol. 61, supplement 2, pp. 96ii-99, 2002.

[34] P. Lankinen, T. J. Mäkinen, T. A. Pöyhönen et al., " $68 \mathrm{Ga}-$ DOTAVAP-P1 PET imaging capable of demonstrating the phase of inflammation in healing bones and the progress of infection in osteomyelitic bones," European Journal of Nuclear Medicine and Molecular Imaging, vol. 35, no. 2, pp. 352-364, 2008.

[35] M. Nahrendorf, E. Keliher, P. Panizzi et al., "18F-4V for PETCT imaging of VCAM-1 expression in atherosclerosis," JACC Cardiovascular Imaging, vol. 2, no. 10, pp. 1213-1222, 2009.

[36] F. Pugliese, O. Gaemperli, A. R. Kinderlerer et al., "Imaging of vascular inflammation with [11C]-PK11195 and positron emission tomography/computed tomography angiography," Journal of the American College of Cardiology, vol. 56, no. 8, pp. 653-661, 2010.

[37] F. Zavala, J. Haumont, and M. Lenfant, "Interaction of benzodiazepines with mouse macrophages," European Journal of Pharmacology, vol. 106, no. 3, pp. 561-566, 1984.

[38] R. B. Banati, "Visualising microglial activation in vivo," GLIA, vol. 40, no. 2, pp. 206-217, 2002.

[39] A.-C. Dupont, B. Largeau, M. J. S. Ribeiro, D. Guilloteau, C. Tronel, and N. Arlicot, "Translocator protein-18 kDa (TSPO) positron emission tomography (PET) imaging and its clinical impact in neurodegenerative diseases," International Journal of Molecular Sciences, vol. 18, no. 4, article no. 785, 2017.

[40] M. Awad and M. Gavish, "Binding of [3H]Ro 5-4864 and [3H]PK 11195 to Cerebral Cortex and Peripheral Tissues of Various Species: Species Differences and Heterogeneity in Peripheral Benzodiazepine Binding Sites," Journal of Neurochemistry, vol. 49, no. 5, pp. 1407-1414, 1987.

[41] M. Anzini, A. Cappelli, S. Vomero et al., "Molecular basis of peripheral vs central benzodiazepine receptor selectivity in a new class of peripheral benzodiazepine receptor ligands related to alpidem," Journal of Medicinal Chemistry, vol. 39, no. 21, pp. 4275-4284, 1996.

[42] G. Le Fur, M. L. Perrier, N. Vaucher et al., "Peripheral benzodiazepine binding sites: Effect of PK 11195, 1-(2-chlorophenyl)n-methyl-n-(1-methylpropyl)-3-isoquinolinecarboxamide. I. In vitro studies," Life Sciences, vol. 32, no. 16, pp. 1839-1847, 1983.

[43] F. Chauveau, H. Boutin, N. van Camp, F. Dollé, and B. Tavitian, "Nuclear imaging of neuroinflammation: a comprehensive review of $\left[{ }^{11} \mathrm{C}\right]$ PK11195 challengers," European Journal of Nuclear Medicine and Molecular Imaging, vol. 35, no. 12, pp. 2304-2319, 2008.

[44] S. Chaki, T. Funakoshi, R. Yoshikawa et al., "Binding characteristics of [3H]DAA1106, a novel and selective ligand for peripheral benzodiazepine receptors," European Journal of Pharmacology, vol. 371, no. 2-3, pp. 197-204, 1999.

[45] M.-R. Zhang, J. Maeda, K. Furutsuka et al., "[ ${ }^{18}$ F]FMDAA1106 and $\left[{ }^{18} \mathrm{~F}\right]$ FEDAA1106: two positron-emitter labeled ligands for peripheral benzodiazepine receptor (PBR)," Bioorganic and Medicinal Chemistry Letters, vol. 13, no. 2, pp. 201-204, 2003.

[46] W. C. Kreisl, M. Fujita, Y. Fujimura et al., "Comparison of [11C](R)-PK 11195 and [11C]PBR28, two radioligands for translocator protein $(18 \mathrm{kDa})$ in human and monkey: Implications for 
positron emission tomographic imaging of this inflammation biomarker," NeuroImage, vol. 49, no. 4, pp. 2924-2932, 2010.

[47] A. A. Wilson, A. Garcia, J. Parkes et al., "Radiosynthesis and initial evaluation of [18F]-FEPPA for PET imaging of peripheral benzodiazepine receptors," Nuclear Medicine and Biology, vol. 35, no. 3, pp. 305-314, 2008.

[48] S. Selleri, F. Bruni, C. Costagli et al., "2-Arylpyrazolo[1,5a]pyrimidin-3-yl acetamides. New potent and selective peripheral benzodiazepine receptor ligands," Bioorganic and Medicinal Chemistry, vol. 9, no. 10, pp. 2661-2671, 2001.

[49] D. R. Owen, A. J. Yeo, R. N. Gunn et al., "An 18-kDa translocator protein (TSPO) polymorphism explains differences in binding affinity of the PET radioligand PBR28," Journal of Cerebral Blood Flow \& Metabolism, vol. 32, pp. 1-5, 2012.

[50] K. K. Yoder, K. Nho, S. L. Risacher, S. Kim, L. Shen, and A. J. Saykin, "Influence of TSPO genotype on 11C-PBR28 standardized uptake values," Journal of Nuclear Medicine, vol. 54, no. 8, pp. 1320-1322, 2013.

[51] Z. Fan, V. Calsolaro, R. A. Atkinson et al., "Flutriciclamide (18F-GE180) PET: First-in-human PET study of novel thirdgeneration in vivo marker of human translocator protein," Journal of Nuclear Medicine, vol. 57, no. 11, pp. 1753-1759, 2016.

[52] M. Ikawa, T. G. Lohith, S. Shrestha et al., "11C-ER176, a radioligand for $18-\mathrm{kDa}$ translocator protein, has adequate sensitivity to robustly image all three affinity genotypes in human brain," Journal of Nuclear Medicine, vol. 58, no. 2, pp. 320-325, 2017.

[53] R. Dessein, M. Chamaillard, and S. Danese, "Innate immunity in Crohn's disease," Journal of Clinical Gastroenterology, vol. 42, pp. S144-S147, 2008.

[54] D. Ellinghaus, J. Bethune, B.-S. Petersen, and A. Franke, "The genetics of Crohn's disease and ulcerative colitis-status quo and beyond," Scandinavian Journal of Gastroenterology, vol. 50, no. 1, pp. 13-23, 2015.

[55] T. Stefanelli, A. Malesci, A. Repici, S. Vetrano, and S. Danese, "New insights into inflammatory bowel disease pathophysiology: paving the way for novel therapeutic targets," Current Drug Targets, vol. 9, no. 5, pp. 413-418, 2008.

[56] G. Solina, S. Mandalà, C. La Barbera, and V. Mandalà, "Current management of intestinal bowel disease: the role of surgery," Updates in Surgery, vol. 68, no. 1, pp. 13-23, 2016.

[57] A. M. McCombie, R. T. Mulder, and R. B. Gearry, "How IBD patients cope with IBD: a systematic review," Journal of Crohn's and Colitis, vol. 7, no. 2, pp. 89-106, 2013.

[58] F. Caobelli, L. Evangelista, N. Quartuccio et al., "Role of molecular imaging in the management of patients affected by inflammatory bowel disease: State-of-the-art," World Journal of Radiology, vol. 8, no. 10, p. 829, 2016.

[59] K. A. Chachu and M. T. Osterman, "How to diagnose and treat IBD mimics in the refractory IBD patient who does not have IBD,' Inflammatory Bowel Diseases, vol. 22, no. 5, pp. 1262-1274, 2016.

[60] C. S. Gismera and B. S. Aladrén, "Inflammatory bowel diseases: a disease (s) of modern times? Is incidence still increasing?" World Journal of Gastroenterology, vol. 14, no. 36, pp. 5491-5498, 2008.

[61] D. Bettenworth, S. Reuter, S. Hermann et al., "Translational 18FFDG PET/CT Imaging to Monitor Lesion Activity in Intestinal Inflammation," Journal of Nuclear Medicine, vol. 54, no. 5, pp. 748-755, 2013.

[62] P. Hindryckx, S. Staelens, L. Devisscher et al., "Longitudinal quantification of inflammation in the murine dextran sodium sulfate-induced colitis model using $\mu \mathrm{pET} / \mathrm{CT}$,' Inflammatory Bowel Diseases, vol. 17, no. 10, pp. 2058-2064, 2011.

[63] R. T. Lapp, B. J. Spier, S. B. Perlman, C. J. Jaskowiak, and M. Reichelderfer, "Clinical Utility of Positron Emission Tomography/Computed Tomography in Inflammatory Bowel Disease," Molecular Imaging and Biology, vol. 13, no. 3, pp. 573-576, 2011.

[64] D. A. Lemberg, R. M. Issenman, R. Cawdron et al., "Positron emission tomography in the investigation of pediatric inflammatory bowel disease," Inflammatory Bowel Diseases, vol. 11, no. 8, pp. 733-738, 2005.

[65] M. Löffler, M. Weckesser, C. Franzius, O. Schober, and K.-P. Zimmer, "High diagnostic value of 18F-FDG-PET in pediatric patients with chronic inflammatory bowel disease," Annals of the New York Academy of Sciences, vol. 1072, pp. 379-385, 2006.

[66] R. S. Meisner, B. J. Spier, S. Einarsson et al., "Pilot study using PET/CT as a novel, noninvasive assessment of disease activity in inflammatory bowel disease," Inflammatory Bowel Diseases, vol. 13, no. 8, pp. 993-1000, 2007.

[67] M. Neurath, D. Vehling, K. Schunk et al., "Noninvasive assessment of Crohn's disease activity: a comparison of $18 \mathrm{~F}-$ fluorodeoxyglucose positron emission tomography, hydromagnetic resonance imaging, and granulocyte scintigraphy with labeled antibodies," The American Journal of Gastroenterology, vol. 97, no. 8, pp. 1978-1985, 2002.

[68] J. Däbritz, N. Jasper, M. Loeffler, M. Weckesser, and D. Foell, "Noninvasive assessment of pediatric inflammatory bowel disease with $18 \mathrm{~F}$-fluorodeoxyglucose-positron emission tomography and computed tomography," European Journal of Gastroenterology and Hepatology, vol. 23, no. 1, pp. 81-89, 2011.

[69] G. Treglia, N. Quartuccio, R. Sadeghi et al., "Diagnostic performance of Fluorine-18-Fluorodeoxyglucose positron emission tomography in patients with chronic inflammatory bowel disease: a systematic review and a meta-analysis," Journal of Crohn's and Colitis, vol. 7, no. 5, pp. 345-354, 2013.

[70] Y. Katz, A. Eitan, Z. Amiri, and M. Gavish, "Dramatic increase in peripheral benzodiazepine binding sites in human colonic adenocarcinoma as compared to normal colon," European Journal of Pharmacology, vol. 148, no. 3, pp. 483-484, 1988.

[71] K. Maaser, "Up-Regulation of the Peripheral Benzodiazepine Receptor during Human Colorectal Carcinogenesis and Tumor Spread," Clinical Cancer Research, vol. 11, no. 5, pp. 1751-1756, 2005.

[72] P. Grabowski, K. Maaser, and I. Schindler, "Overexpression of the peripheral benzodiazepine receptor is a relevant prognostic factor in stage III colorectal cancer," Clinical Cancer Research, vol. 8, no. 10, pp. 3205-3209, 2002.

[73] M. A. Ostuni, L. Issop, G. Péranzi et al., "Overexpression of translocator protein in inflammatory bowel disease: potential diagnostic and treatment value," Inflammatory Bowel Diseases, vol. 16, no. 9, pp. 1476-1487, 2010.

[74] D. H. Seo, X. Che, M. S. Kwak et al., "Interleukin-33 regulates intestinal inflammation by modulating macrophages in inflammatory bowel disease," Scientific Reports, vol. 7, no. 1, 2017.

[75] C. J. Beltrán, L. E. Núñez, D. Díaz-Jiménez et al., "Characterization of the novel ST2/IL-33 system in patients with inflammatory bowel disease," Inflammatory Bowel Diseases, vol. 16, no. 7, pp. 1097-1107, 2010.

[76] V. Papadopoulos, M. Baraldi, T. R. Guilarte et al., "Translocator protein $(18 \mathrm{kDa})$ : new nomenclature for the peripheral-type benzodiazepine receptor based on its structure and molecular function," Trends in Pharmacological Sciences, vol. 27, no. 8, pp. 402-409, 2006. 
[77] S. Savino, N. Denora, R. M. Iacobazzi et al., "Synthesis, Characterization, and Cytotoxicity of the First Oxaliplatin Pt(IV) Derivative Having a TSPO Ligand in the Axial Position," International Journal of Molecular Sciences, vol. 17, no. 7, 2016.

[78] M. Liu, Y. Dou, R. Sun, Y. Zhang, and Y. Liu, "Molecular Mechanisms for Alcoholic Hepatitis Based on Analysis of Gene Expression Profile," Hepatitis Monthly, vol. 15, no. 5, p. e27336, 2015.

[79] L. Xie, J. Yui, A. Hatori et al., "Translocator protein (18 kDa), a potential molecular imaging biomarker for non-invasively distinguishing non-alcoholic fatty liver disease," Journal of Hepatology, vol. 57, no. 5, pp. 1076-1082, 2012.

[80] A. Hatori, J. Yui, L. Xie et al., "Utility of Translocator Protein $(18 \mathrm{kDa})$ as a Molecular Imaging Biomarker to Monitor the Progression of Liver Fibrosis," Scientific Reports, vol. 5, no. 1, 2015.

[81] R. Fischer, M. Schmitt, J. G. Bode, and D. Häussinger, "Expression of the peripheral-type benzodiazepine receptor and apoptosis induction in hepatic stellate cells," Gastroenterology, vol. 120, no. 5, pp. 1212-1226, 2001.

[82] E. Campioli, G. Carnevale, R. Avallone, D. Guerra, and M. Baraldi, "Morphological and receptorial changes in the epididymal adipose tissue of rats subjected to a stressful stimulus," Obesity, vol. 19, no. 4, pp. 703-708, 2011.

[83] N. Wang, H. Liang, and K. Zen, "Molecular mechanisms that influence the macrophage M1-M2 polarization balance," Frontiers in Immunology, vol. 5, article 614, 2014.

[84] S. Capitanio, A. J. Nordin, A. R. Noraini, and C. Rossetti, "PET/CT in nononcological lung diseases: Current applications and future perspectives," European Respiratory Review, vol. 25, no. 141, pp. 247-258, 2016.

[85] H. M. Branley, R. M. du Bois, A. U. Wells, and H. A. Jones, "PET scanning of macrophages in patients with scleroderma fibrosing alveolitis," Nuclear Medicine and Biology, vol. 35, no. 8, pp. 901909, 2008.

[86] S. Goel and R. Gadiraju, "Diffuse lung uptake of 11lin octreotide from chronic emphysema," Journal of Nuclear Medicine Technology, vol. 41, no. 2, pp. 117-118, 2013.

[87] S. H. Saverymuttu, G. Phillips, A. M. Peters, and J. P. Lavender, "Indium 111 autologous leucocyte scanning in lobar pneumonia and lung abscesses," Thorax, vol. 40, no. 12, pp. 925-930, 1985.

[88] H. A. Jones, S. Sriskandan, A. M. Peters et al., "Dissociation of neutrophil emigration and metabolic activity in lobar pneumonia and bronchiectasis," European Respiratory Journal, vol. 10, no. 4, pp. 795-803, 1997.

[89] E. Bribes, D. Carrière, C. Goubet, S. Galiègue, P. Casellas, and S. Joêlle, "Immunohistochemical Assessment of the Peripheral Benzodiazepine Receptor in Human Tissues," Journal of Histochemistry \& Cytochemistry, vol. 52, no. 1, pp. 19-28, 2016.

[90] J. C. Mak and P. J. Barnes, "Peripheral type benzodiazepine receptors in human and guinea pig lung: characterization and autoradiographic mapping," Journal of Pharmacology and Experimental Therapeutics, vol. 252, pp. 880-885, 1990.

[91] H. A. Jones, S. O. Valind, I. C. Clark et al., "Kinetics of lung macrophages monitored in vivo following particulate challenge in rabbits," Toxicology and Applied Pharmacology, vol. 183, no. 1, pp. 46-54, 2002.

[92] L. Zuo, K. Lucas, C. A. Fortuna, C. Chuang, and T. M. Best, "Molecular regulation of toll-like receptors in asthma and COPD," Frontiers in Physiology, vol. 6, article 312, 2015.
[93] Y. Duan, M. Zhou, J. Xiao et al., "Prediction of key genes and miRNAs responsible for loss of muscle force in patients during an acute exacerbation of chronic obstructive pulmonary disease," International Journal of Molecular Medicine, vol. 38, no. 5, pp. 1450-1462, 2016.

[94] Y. Chen and J. Qiao, "Protein-protein interaction network analysis and identifying regulation microRNAs in asthmatic children," Allergologia et Immunopathologia, vol. 43, no. 6, pp. 584-592, 2015.

[95] T. Becker, F.-N. Vögtle, D. Stojanovski, and C. Meisinger, "Sorting and assembly of mitochondrial outer membrane proteins," Biochimica et Biophysica Acta - Bioenergetics, vol. 1777, no. 7-8, pp. 557-563, 2008.

[96] J. Gatliff, D. East, J. Crosby et al., "TSPO interacts with VDAC1 and triggers a ROS-mediated inhibition of mitochondrial quality control," Autophagy, vol. 10, no. 12, pp. 2279-2296, 2015.

[97] F. Li, J. Liu, N. Liu, L. A. Kuhn, R. M. Garavito, and S. FergusonMiller, "Translocator Protein $18 \mathrm{kDa}$ (TSPO): An Old Protein with New Functions?" Biochemistry, vol. 55, no. 20, pp. 28212831, 2016.

[98] O. A. Jaffer, A. B. Carter, P. N. Sanders et al., "MitochondrialTargeted Antioxidant Therapy Decreases Transforming Growth Factor- $\beta$-Mediated Collagen Production in a Murine Asthma Model," American Journal of Respiratory Cell and Molecular Biology, vol. 52, no. 1, pp. 106-115, 2015.

[99] D. J. Rowlands, "Mitochondria dysfunction: a novel therapeutic target in pathological lung remodeling or bystander?" Pharmacology and Therapeutics, vol. 166, pp. 96-105, 2016.

[100] H. A. Jones, P. S. Marino, B. H. Shakur, and N. W. Morrell, "In vivo assessment of lung inflammatory cell activity in patients with COPD and asthma," European Respiratory Journal, vol. 21, no. 4, pp. 567-573, 2003.

[101] M. Gavish, S. Cohen, and R. Nagler, "Cigarette smoke effects on TSPO and VDAC expression in a cellular lung cancer model," European Journal of Cancer Prevention, vol. 25, no. 5, pp. 361367, 2016.

[102] H. M. Branley, R. M. du Bois, A. U. Wells, and H. A. Jones, "Peripheral-type benzodiazepine receptors in bronchoalveolar lavage cells of patients with interstitial lung disease," Nuclear Medicine and Biology, vol. 34, no. 5, pp. 553-558, 2007.

[103] R. M. Silver, K. S. Miller, M. B. Kinsella, E. A. Smith, and S. I. Schabel, "Evaluation and management of scleroderma lung disease using bronchoalveolar lavage," The American Journal of Medicine, vol. 88, no. 5, pp. 470-476, 1990.

[104] S. H. Audi, C. A. Dawson, S. B. Ahlf, and D. L. Roerig, "Lung tissue mitochondrial benzodiazepine receptors increase in a model of pulmonary inflammation," Lung, vol. 180, no. 5, pp. 241-250, 2002.

[105] X. Qi, J. Xu, F. Wang, and J. Xiao, “Translocator protein $(18 \mathrm{kDa})$ : A promising therapeutic target and diagnostic tool for cardiovascular diseases," Oxidative Medicine and Cellular Longevity, Article ID 162934, 2012.

[106] C. M. Weyand and J. J. Goronzy, "Medium- and Large-Vessel Vasculitis," New England Journal of Medicine, vol. 349, no. 2, pp. 160-169, 2003.

[107] FD. Carmona, P. Coit, G. Saruhan-Direskeneli et al., "Analysis of the common genetic component of large-vessel vasculitides through a meta-Immunochip strategy," Scientific Reports, vol. 7, p. $43953,2017$.

[108] FD. Carmona, SL. Mackie, J-E. Martín et al., "A large-scale genetic analysis reveals a strong contribution of the HLA class 
II region to giant cell arteritis susceptibility," American Journal of Human Genetics, vol. 96, pp. 565-580, 2015.

[109] G. Saruhan-Direskeneli, T. Hughes, K. Aksu et al., "Identification of Multiple Genetic Susceptibility Loci in Takayasu Arteritis," American Journal of Human Genetics, vol. 93, pp. 298305, 2013.

[110] F. Lamare, R. Hinz, O. Gaemperli et al., "Detection and Quantification of Large-Vessel Inflammation with 11C-(R)-PK11195 PET/CT,' Journal of Nuclear Medicine, vol. 52, no. 1, pp. 33-39, 2010.

[111] B. Seeliger, J. Sznajd, J. C. Robson et al., "Are the 1990 American College of Rheumatology vasculitis classification criteria still valid?" Rheumatology, vol. 56, no. 7, pp. 1154-1161, 2017.

[112] A. Lekic, Z. Brekalo, A. Kvesic et al., "Cross-talk Between Enzymes Matrix-metalloproteinsese 2 and 9 and Regulatory T-cell Immunity in the Global Burden of Atherosclerosis," Scandinavian Journal of Immunology, vol. 86, no. 1, pp. 65-71, 2017.

[113] P. Libby, "Inflammation in atherosclerosis," Nature, vol. 420, no. 6917, pp. 868-874, 2002.

[114] Q. Li, Y. Wang, H. Li, G. Shen, and S. Hu, "Ox-LDL influences peripheral Th17/treg balance by modulating treg apoptosis and Th17 proliferation in atherosclerotic cerebral infarction," Cellular Physiology and Biochemistry, vol. 33, no. 6, pp. 18491862, 2014.

[115] A. M. Lundberg and G. K. Hansson, "Innate immune signals in atherosclerosis," Clinical Immunology, vol. 134, no. 1, pp. 5-24, 2010.

[116] N. Sasaki, T. Yamashita, M. Takeda, and K.-I. Hirata, "Regulatory T cells in atherogenesis," Journal of Atherosclerosis and Thrombosis, vol. 19, no. 6, pp. 503-515, 2012.

[117] J. M. W. Taylor, A.-M. Allen, and A. Graham, "Targeting mitochondrial $18 \mathrm{kDa}$ translocator protein (TSPO) regulates macrophage cholesterol efflux and lipid phenotype," Clinical Science, vol. 127, no. 10, pp. 603-613, 2014.

[118] L. Veenman, V. Papadopoulos, and M. Gavish, "Channel-like functions of the 18-kDA translocator protein (TSPO): Regulation of apoptosis and steroidogenesis as part of the host-defense response," Current Pharmaceutical Design, vol. 13, no. 23, pp. 2385-2405, 2007.

[119] L. Veenman and M. Gavish, "The peripheral-type benzodiazepine receptor and the cardiovascular system. Implications for drug development," Pharmacology and Therapeutics, vol. 110, no. 3, pp. 503-524, 2006.

[120] S. Cuhlmann, W. Gsell, K. Van Der Heiden et al., "In vivo mapping of vascular inflammation using the translocator protein tracer 18F-FEDAA1106," Molecular Imaging, vol. 13, no. 6, 2014.

[121] S. Hellberg, J. M. Silvola, M. Kiugel et al., "18-kDa translocator protein ligand 18F-FEMPA: biodistribution and uptake into atherosclerotic plaques in mice," Journal of Nuclear Cardiology, vol. 24, no. 3, pp. 862-871, 2017.

[122] O. Gaemperli, J. Shalhoub, and D. R. J. Owen, "Imaging intraplaque inflammation in carotid atherosclerosis with ${ }^{11} \mathrm{C}$ PK11195 positron emission tomography/computed tomography," European Heart Journal, vol. 33, no. 15, pp. 1902-1910, 2012.

[123] G. Chinetti-Gbaguidi, M. Daoudi, M. Rosa et al., "Human Alternative Macrophages Populate Calcified Areas of Atherosclerotic Lesions and Display Impaired RANKL-Induced Osteoclastic Bone Resorption ActivityNovelty and Significance," Circulation Research, vol. 121, no. 1, pp. 19-30, 2017.
[124] J. Dimitrova-Shumkovska, L. Veenman, T. Ristoski, S. Leschiner, and M. Gavish, "Chronic high fat, high cholesterol supplementation decreases $18 \mathrm{kDa}$ Translocator Protein binding capacity in association with increased oxidative stress in rat liver and aorta," Food and Chemical Toxicology, vol. 48, no. 3, pp. 910-921, 2010.

[125] C. J. van der Laken, E. H. Elzinga, and M. A. Kropholler, "Noninvasive imaging of macrophages in rheumatoid synovitis using ${ }^{11} \mathrm{C}-(R)$-PK11195 and positron emission tomography," Arthritis \& Rheumatism, vol. 58, no. 11, pp. 3350-3355, 2008.

[126] V. F. Derksen, T. W. Huizinga, and D. van der Woude, "The role of autoantibodies in the pathophysiology of rheumatoid arthritis," Seminars in Immunopathology, vol. 39, no. 4, pp. 437446, 2017.

[127] E. S. Norli, G. H. Brinkmann, T. K. Kvien et al., "Self-limiting arthritis among patients fulfilling the 2010 ACR/EULAR classification criteria for rheumatoid arthritis in a very early arthritis cohort," Seminars in Arthritis and Rheumatism, vol. 46, no. 3, pp. 272-278, 2016.

[128] X. Shao, X. Wang, S. J. English et al., "Imaging of carrageenaninduced local inflammation and adjuvant-induced systemic arthritis with [11C]PBR28 PET,' Nuclear Medicine and Biology, vol. 40, no. 7, pp. 906-911, 2013.

[129] Y. Y. J. Gent, K. Weijers, C. F. M. Molthoff et al., "Promising potential of new generation translocator protein tracers providing enhanced contrast of arthritis imaging by positron emission tomography in a rat model of arthritis," Arthritis Research and Therapy, vol. 16, no. 2, article R70, 2014.

[130] G. Pottier, N. Bernards, F. Dollé, and R. Boisgard, "[ $\left.{ }^{18} F\right] D P A-$ 714 as a biomarker for positron emission tomography imaging of rheumatoid arthritis in an animal model," Arthritis Research \& Therapy, vol. 16, no. 2, article R69, 2014.

[131] M. Politis, N. Lahiri, F. Niccolini et al., "Increased central microglial activation associated with peripheral cytokine levels in premanifest Huntington's disease gene carriers," Neurobiology of Disease, vol. 83, pp. 115-121, 2015.

[132] L. Hamelin, J. Lagarde, G. Dorothée et al., "Early and protective microglial activation in Alzheimer's disease: A prospective study using 18F-DPA-714 PET imaging," Brain, vol. 139, no. 4, pp. 1252-1264, 2016.

[133] B. Zinnhardt, T. Viel, L. Wachsmuth et al., "Multimodal imaging reveals temporal and spatial microglia and matrix metalloproteinase activity after experimental stroke," Journal of Cerebral Blood Flow \& Metabolism, 2015.

[134] T. Notter, J. M. Coughlin, T. Gschwind et al., "Translational evaluation of translocator protein as a marker of neuroinflammation in schizophrenia," Molecular Psychiatry, 2017.

[135] P. Iversen, D. A. Hansen, D. Bender et al., "Peripheral benzodiazepine receptors in the brain of cirrhosis patients with manifest hepatic encephalopathy," European Journal of Nuclear Medicine and Molecular Imaging, vol. 33, no. 7, pp. 810-816, 2006.

[136] E. Kurtys, J. Doorduin, U. L. M. Eisel, R. A. J. O. Dierckx, and E. F. J. de Vries, "Evaluating [11C]PBR28 PET for Monitoring Gut and Brain Inflammation in a Rat Model of Chemically Induced Colitis," Molecular Imaging and Biology, vol. 19, no. 1, pp. 68-76, 2017.

[137] J. H. Vera, Q. Guo, J. H. Cole et al., "Neuroinflammation in treated HIV-positive individuals: A TSPO PET study," Neurology, vol. 86, no. 15, pp. 1425-1432, 2016.

[138] J. Hannestad, J.-D. Gallezot, T. Schafbauer et al., "Endotoxin-induced systemic inflammation activates microglia: [11C]PBR28 
positron emission tomography in nonhuman primates," NeuroImage, vol. 63, no. 1, pp. 232-239, 2012.

[139] L. Beckers, D. Ory, I. Geric et al., "Increased Expression of Translocator Protein (TSPO) Marks Pro-inflammatory Microglia but Does Not Predict Neurodegeneration," Molecular Imaging and Biology.

[140] C. Wu, X. Yue, L. Lang et al., "Longitudinal PET imaging of muscular inflammation using 18F-DPA-714 and 18F-alfatide II and differentiation with tumors," Theranostics, vol. 4, no. 5, pp. 546-555, 2014. 


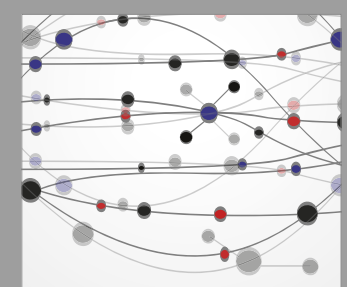

The Scientific World Journal
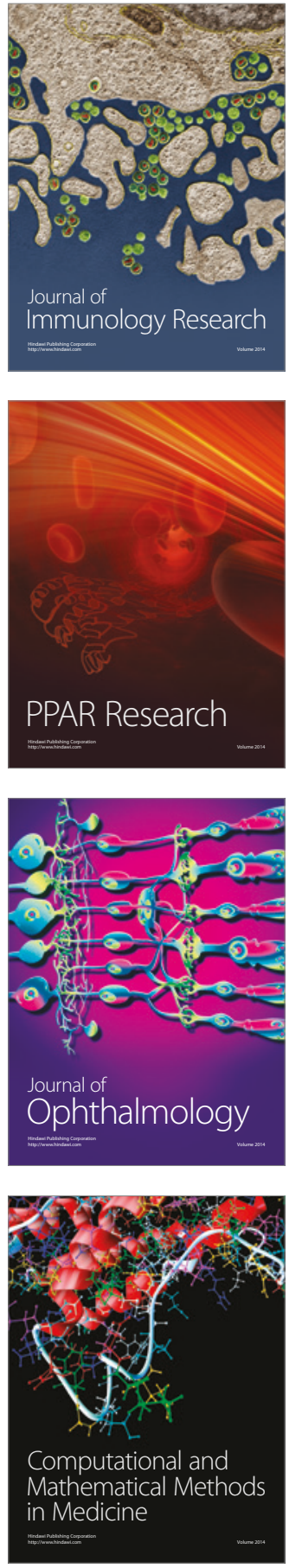

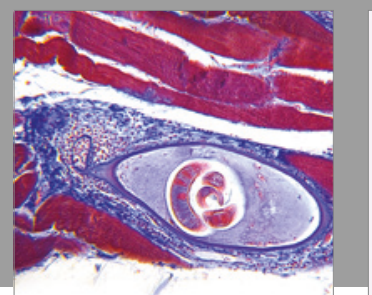

Gastroenterology Research and Practice
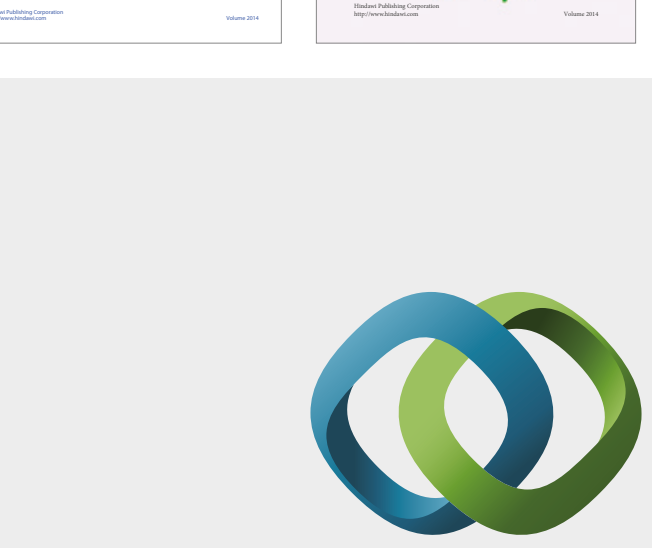

\section{Hindawi}

Submit your manuscripts at

https://www.hindawi.com
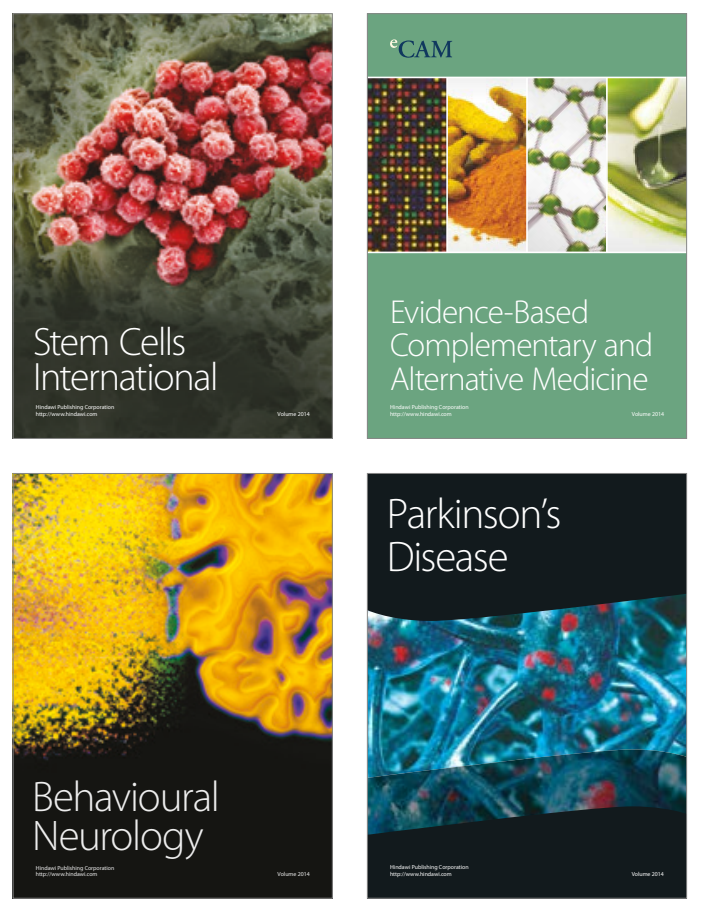
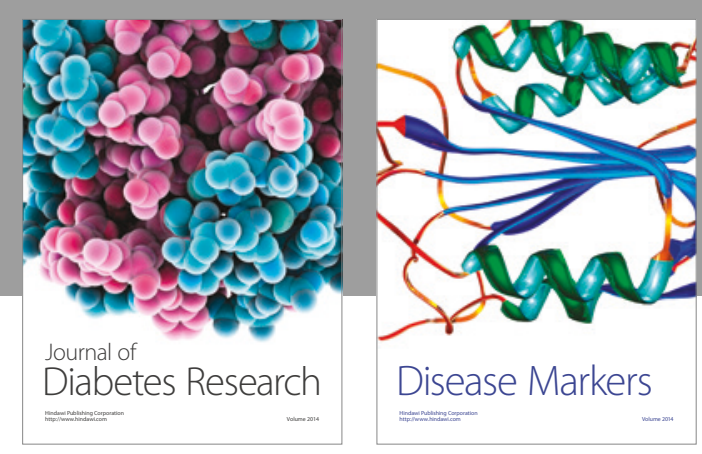

Disease Markers
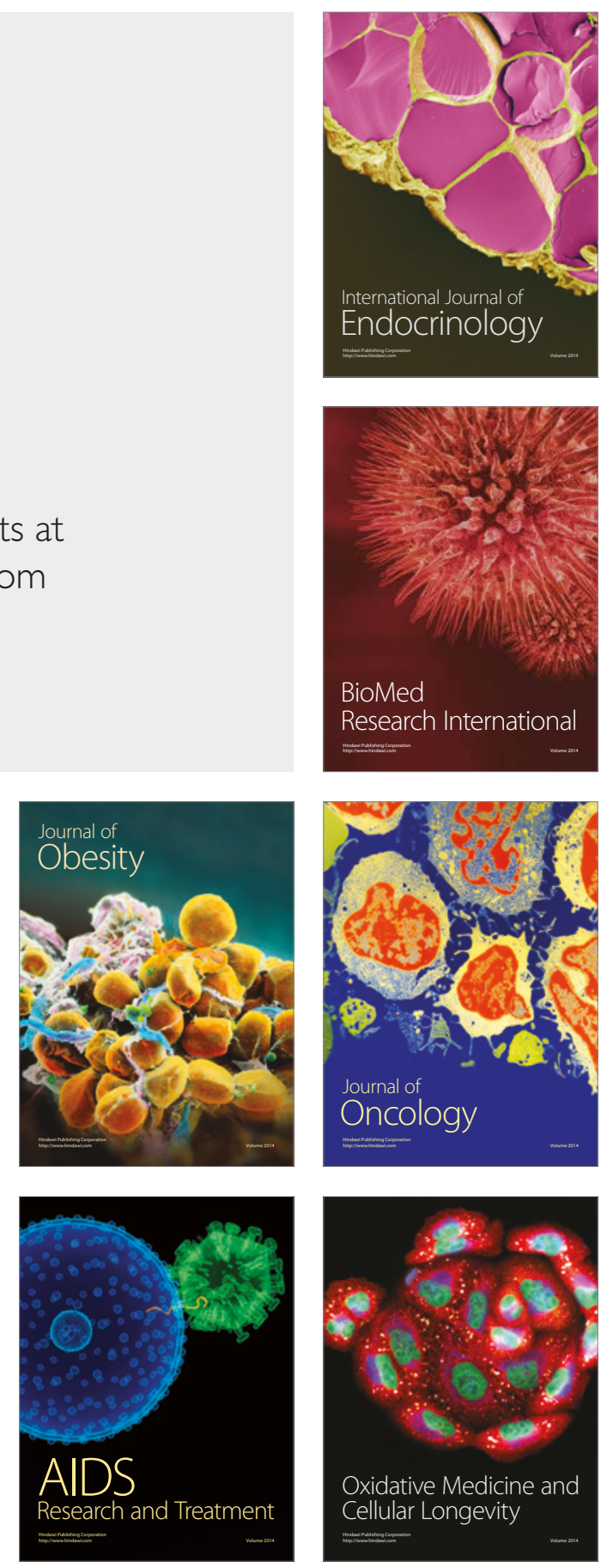